\title{
Políticas de apoyo a las familias en la Unión Europea y en la CAPV
}

\section{SIIS Centro de Documentación y Estudios}

Fundación Eguía-Careaga

<estudios@siis.net>

Eusko Jaurlaritzaren Familia eta Komunitate Politikarako Zuzendaritzak eskatuta, SIIS Dokumentazio eta Ikerketa Zentroak egindako Euskadiko familia-politiken inguruko azterlan bat laburki azaltzen du artikulu honek. Palier, Palme, Morel edo Esping-Andersen egileek garatutako Estatu sozial inbestitzailearen paradigma testuinguruan kokatzen du, eta bertan konparazioa burutzen da EAEko laguntza eta gastuaren maila eta erreferente gisara hartutako herrialde eta erkidegoekin. Bikoitza da analisiak lortutako ondorio nagusia. Batetik, ez dago esaterik Euskadin paradigma horretara gerturatzeko adina urratsik eman denik. Bestetik, beste herrialdeekin alderatuz, EAEn garapen eskasa izan du prestazio eta zerbitzuen eredu horrek.

\section{HITZ-GAKOAK:}

familia-politika, prestazio ekonomikoak, azterlan konparatiboa, EAE, Europar Batasuna.
Este artículo resume un informe más amplio elaborado por el SIIS Centro de Documentación y Estudios, a instancias de la Dirección de Política Familiar y Comunitaria del Gobierno Vasco, en torno a las políticas de apoyo a las familias en Euskadi. Además de contextualizar las políticas familiares en el marco del paradigma del Estado social inversor desarrollado por autores como Palier, Palme, Morel o Esping-Andersen, el informe compara las ayudas existentes en la CAPV, así como el gasto a ellas destinado, con las que existen en los países y comunidades utilizados como referencia. La conclusión que se deriva del análisis es doble. Por una parte, no puede decirse que en Euskadi se estén dando todos los pasos necesarios para adoptar el paradigma del Estado social inversor. Por otra, el modelo de prestaciones y servicios que existe en la CAPV está muy escasamente desarrollado si se compara con el de la mayor parte de los países analizados.

\section{Palabras Clave:}

política familiar, prestaciones económicas, estudio comparativo, CAPV, Unión Europea. 


\section{Introducción: objetivos y metodología}

El objetivo de este artículo es contextualizar las políticas de apoyo a las familias que se realizan en la Comunidad Autónoma del País Vasco en relación a las que se realizan en otros países de Europa y en otras comunidades autónomas del Estado español. A partir de un informe previo, encargado por la Dirección de Política Familiar y Comunitaria del Gobierno Vasco, en el que se describen de la forma más detallada posible las prestaciones y servicios que existen en una serie de países y comunidades autónomas -considerados por diversas razones como paradigmáticos o ejemplares-y se comparan con las que existen actualmente en la CAPV, el objetivo de este artículo es poder determinar en qué medida las políticas vascas de apoyo a las familias con hijos e hijas se acercan a los patrones de intervención de esos países y comunidades.

La primera parte del artículo describe los argumentos teóricos de quienes defienden una mayor centralidad de las políticas de apoyo a las familias, en el marco del Estado de bienestar, de acuerdo con el paradigma del Estado social inversor. Se describen en ese sentido los argumentos de quienes consideran que el gasto en políticas de apoyo a las familias debe ser considerado como una inversión, en razón de su mayor eficiencia y de sus elevadas tasas de retorno, respecto a otros ámbitos de las políticas sociales. De acuerdo a estos autores, y como se señala más adelante, el refuerzo de las políticas de apoyo a las familias es uno de los ejes fundamentales de una nueva aproximación al Estado de bienestar, mucho más orientada a la eficiencia, a la inversión productiva y a la búsqueda de una mayor igualdad de oportunidades.

La segunda parte del informe analiza en detalle la situación de las políticas vascas de apoyo a las familias, fundamentalmente en términos de gasto público, a partir de las estadísticas de la Cuenta de la Protección Social de Eustat, para la CAPV, y de Eurostat, para los países de la UE. También se incluye en este artículo información sobre el gasto en educación infantil o preprimaria a partir de la Cuenta de la Educación de Eustat y de las estadísticas europeas de Eurostat sobre el gasto en educación.

La última parte del artículo resume los resultados básicos que se derivan de esta comparación y plantea, a la luz de esas conclusiones, algunas recomendaciones genéricas.

La metodología que se ha seguido para la realización de este informe es la siguiente:

- La reflexión teórica recogida en la primera parte se ha realizado fundamentalmente a partir de una revisión de la literatura científica existente sobre esta materia. Para la búsqueda y el análisis documental, se ha recurrido a la base de datos bibliográfica sobre servicios y políticas sociales del SIIS Centro de Documentación y Estudios.
- El análisis de los datos económicos se ha realizado a partir, fundamentalmente, de las estadísticas de la Cuenta de la Protección Social de Eustat, para la CAPV, y del Sistema Europeo de Cuentas Integradas de Protección Social (SEEPROS) de Eurostat para la UE. Ambas estadísticas utilizan la misma metodología y sus datos pueden considerarse comparables. También se ha utilizado la base de datos sobre gasto social público de la OCDE, las estadísticas sobre gasto en protección social publicadas por el Gobierno de Navarra y la Generalitat de Cataluña, e información sobre el gasto en educación infantil o preprimaria a partir de la Cuenta de la Educación de Eustat y de las estadísticas europeas de Eurostat sobre gasto educativo.

- Para la descripción de las prestaciones de apoyo a las familias, se ha recurrido fundamentalmente al Sistema de Información Mutua sobre Protección Social de la Unión Europea (MISSOC), que ofrece información detallada acerca de la diferentes políticas de protección social en la UE y en Islandia, Liechtenstein, Noruega y Suiza. Se ha recurrido también a la información sobre políticas familiares que ofrece el Consejo de Europa y a diversos documentos monográficos, así como a las páginas webs de las entidades gestoras de las ayudas analizadas.

A la hora de seleccionar los países y comunidades en relación a los que realizar las comparaciones, se han tenido en cuenta los siguientes criterios:

- En el caso de los países de Europa, se ha elegido un país que pueda corresponder a cada uno de los modelos de bienestar a los que se hace referencia: Italia, como país mediterráneo; Alemania, como país centroeuropeo; y Suecia, como país nórdico. Se han añadido además dos países caracterizados por el amplio desarrollo de sus políticas familiares, como Francia y Noruega. No se han incluido, debido a su escaso peso en el marco de las políticas sociales europeas, países que puedan ser considerados representantes del modelo anglosajón (particularmente, el Reino Unido).

- En el caso de las comunidades autónomas, se ha procurado ofrecer información de una comunidad cercana que disfruta de un marco de financiación similar al de la CAPV (la Comunidad Foral Navarra) y de dos comunidades (Cataluña y Madrid) ampliamente pobladas y que, como la CAPV, tienen un desarrollo económico superior a la media estatal. En el caso de Cataluña y de Navarra, se ha tenido también en cuenta la existencia de datos estadísticos, obtenidos mediante la metodología SEEPROS, sobre gasto en protección social.

Es importante destacar en cualquier caso, para comprender las conclusiones del artículo, que la información recogida se refiere exclusivamente a lo que las fuentes consultadas engloban en el ámbito de las políticas de apoyo a las familias con hijos/as. 
No se tiene, por tanto, en cuenta la existencia de servicios o prestaciones económicas -en el ámbito de la educación (salvo en el caso de la educación infantil o preprimaria1 ${ }^{1}$, la vivienda, la salud, los servicios sociales o las prestaciones de garantía de ingresosque influyen directamente en la calidad de vida de las familias. Además, en lo que se refiere a las políticas específicamente destinadas a las familias con hijos/ as, se han tenido fundamentalmente en cuenta las prestaciones económicas directas, debido a que la información sobre los servicios de atención directa está más dispersa y resulta más difícil de obtener.

\section{La nueva centralidad de las políticas de apoyo a las familias}

\subsection{El Estado social inversor: ¿un nuevo paradigma para la definición de las políticas sociales?}

El Estado de bienestar, desde sus inicios, ha estado sometido a múltiples y continuas reformas, al objeto de adaptarlo tanto a los cambios en las necesidades y en las estructuras sociales y económicas, como a los cambios en las orientaciones políticas e ideológicas. Desde mediados de los años noventa y, con más claridad, a partir de los primeros años del siglo XXI, se ha ido desarrollando sobre todo en Europa un enfoque que, para muchos, implica un cambio de paradigma en la definición de las políticas de bienestar social y que, como se señala más adelante, trae aparejado un cambio fundamental en el papel de las políticas de apoyo a las familias con hijos/as, otorgándoles una nueva o mayor centralidad en el conjunto de las políticas de protección social.

Aunque este nuevo enfoque ha sido denominado de muy diversas formas -liberalismo inclusivo, Estado capacitador, Estado de inversión social, entre otras-, en los últimos años ha ido consolidándose para su definición el término de Estado social inversor (social investment welfare state). La principal característica de este enfoque es, tal y como han señalado Morel, Palier y Palme (2012), el cambio de énfasis desde unas políticas orientadas a la reparación a otras orientadas a la preparación (preparing rather than repairing). De acuerdo a estos autores, el enfoque de la inversión social se basa en políticas que buscan tanto el desarrollo del capital humano (cuidados infantiles y educación precoz, formación a lo largo de toda la vida) y el aprovechamiento eficiente de ese capital (mediante políticas que favorecen la combinación de flexibilidad y seguridad), como la consecución de mayores cotas de inclusión social, fundamentalmente mediante el acceso al mercado de trabajo de grupos tradicionalmente excluidos de él ${ }^{2}$. En

${ }^{1}$ La educación infantil o preprimaria, englobada en las estadísticas educativas en el epígrafe ISCED o, es la que se realiza antes del periodo de escolarización obligatoria. Su inclusión en este informe se debe a que, junto a las guarderías, suponen una herramienta más para la atención infantil y la conciliación de las responsabilidades familiares y laborales.

2 Desde ese punto de vista, puede pensarse que este enfoque se relaciona de forma directa con el paradigma de la inclusión activa cualquier caso, un elemento distintivo básico de este enfoque es la idea de que las políticas sociales deben considerarse como un elemento productivo, esencial para el desarrollo económico y el crecimiento del empleo, lo que constituye un cambio radical con la consideración de las políticas sociales como una carga económica y un obstáculo al crecimiento.

Como ha señalado Gøsta Esping-Andersen (2002), el concepto de política social productiva que subyace al enfoque del Estado social inversor aspiraba a reconciliar los objetivos de equidad y eficiencia, a menudo considerados como opuestos o antagónicos. Según este autor, sin embargo, la equidad no es únicamente compatible con la eficiencia, sino, realmente, un requisito para su optimización: "Una capacidad adquisitiva distribuida de forma más igualitaria es una precondición para el rendimiento macroeconómico; las políticas de apoyo a las familias son una inversión en el capital humano del futuro; la igualación de los recursos, como la salud o la educación, es la base de una productividad laboral óptima". Efectivamente, la perspectiva de la política social productiva parece capaz de resolver la tensión entre la seguridad individual y la solidaridad social, por un lado, y el interés colectivo de la eficiencia económica y la participación productiva individual, por otro, reconciliando de esa forma la lógica de los derechos y la lógica de las responsabilidades.

El nuevo modelo plantea por tanto un funcionamiento mucho más eficiente del Estado de bienestar, basado en la necesidad de orientar el gasto a aquellos ámbitos en los que el esfuerzo económico puede resultar a medio y largo plazo más rentable o coste-efectivo, y puede tener un mayor efecto preventivo. Ello exige, por una parte, una reorientación en las prioridades del gasto social y, por otra, un mayor énfasis en la necesidad de demostrar los resultados, tanto en términos de eficacia como de eficiencia, de los programas públicos de protección social.

Diversos autores, como Morel, Palier y Palme (2012) o Esping-Andersen (2002) sitúan los antecedentes de este enfoque en los postulados desarrollados en los años treinta del pasado siglo por Gunnar y Alva Myrdal, una pareja de pensadores socialdemócratas suecos galardonados con el Premio Nobel de la Paz, ella, y de Economía, él. A ellos se debe el concepto de política social productiva, mediante el cual defendían la necesidad de orientar las políticas sociales hacia una organización más eficiente de la producción y la reproducción, y mediante el cual defendían la consideración de las políticas sociales como una inversión y no como un gasto. Se trata por tanto, como veremos más adelante, de un referente estrechamente vinculado a la definición de las políticas de apoyo a las familias (desde una perspectiva claramente natalista, en cualquier caso) y a la igualdad de género.

desarrollado, con enfoques y acentos distintos, en la mayor parte de los países de la UE en el ámbito de las prestaciones de garantía de ingresos (SIIS, 2011). 
Morel, Palier y Palme (2012) plantean que el enfoque original del Estado social inversor responde en buena medida a los planteamientos keynesianos del Estado de bienestar clásico, si bien implica cambios importantes con respecto a aquel modelo y recoge algunas de las críticas que desde la perspectiva neoliberal se le hicieron. Desde ese punto de vista, el modelo del Estado social inversor apuesta en mayor medida por la inclusión laboral femenina y la igualdad de género -frente a un Estado de bienestar clásico más basado en la familia tradicional y el male breadwiner model-, así como por una concepción más activa de las políticas sociales, frente al carácter pasivo que se le suele atribuir al modelo de protección social clásico. De la perspectiva neoliberal puede pensarse, a juicio de estos autores, que el Estado social inversor adopta la necesidad de adoptar una perspectiva que tenga en cuenta los efectos que las políticas sociales tienen a medio y largo plazo, y no sólo sus efectos inmediatos, así como el énfasis en la activación y la incentivación laboral.

Para estos autores, en efecto, el paradigma del Estado social inversor supone una modernización del Estado de bienestar clásico al objeto de responder mejor a las nuevas necesidades y a los nuevos riesgos sociales, para poder garantizar la sostenibilidad de los servicios sociales, y para impulsar su función 'productiva', en el sentido de que deben contribuir al empleo y el crecimiento económico. Una característica central de este enfoque modernizador es la idea de que las políticas sociales deben orientarse a 'preparar' a la población para prevenir ciertos riesgos relacionados con la mayor inestabilidad laboral y familiar de las sociedades contemporáneas, y a minimizar la transmisión intergeneracional de la pobreza, más que a 'reparar' mediante prestaciones de garantía de ingresos las consecuencias de esos cambios una vez se han producido. Desde ese punto de vista, este tipo de enfoques comparten con el neoliberalismo la idea de que el Estado de bienestar debe buscar la activación de la ciudadanía y su responsabilización mediante la participación en el mercado de trabajo. A diferencia de los planteamientos activadores habituales, sin embargo, el Estado social inversor es crítico con la idea de que cualquier empleo es positivo para el bienestar de las familias y defiende la necesidad de que el Estado del bienestar -en la línea de las políticas de making work pay o rentabilización del empleo- contribuya al desarrollo de empleos de calidad (Morel, Palier y Palme, 2012).

\subsection{La necesidad de invertir en las familias}

Si hay un ámbito de las políticas sociales en el que el cambio de enfoque que supone Estado social inversor incide de forma clara y determinante, es el de las políticas de apoyo a las familias, en la medida en que ganan una centralidad de la que hasta el momento han carecido en la mayor parte de los países. Invertir en el bienestar de la infancia y, por extensión, de las familias constituye el eje del estado social inversor a partir de la defensa de una estrategia de inversión social basada en la infancia (Esping-Andersen, 2002). La base de esa estrategia radica en la idea de que los mecanismos que inciden en la desigualdad y la exclusión operan fundamentalmente durante la primera infancia y se concentran sobre todo en el seno de la familia. Cualquier política eficaz de redistribución, igualdad de oportunidades y lucha contra la exclusión debe por tanto centrarse, prioritariamente, en esa época y en ese ámbito.

Efectivamente, como ha señalado Morgan (2012), las políticas de conciliación de la vida familiar y laboral son uno de los ejes centrales del enfoque del Estado social inversor. Los programas de calidad orientados a la educación precoz y a los cuidados infantiles invierten tanto en el desarrollo cognitivo de los niños/as como en las capacidades laborales de sus madres, permitiéndoles acceder al mercado remunerado. El empleo de las madres incrementa los ingresos familiares, reduciendo la pobreza infantil y sus efectos a largo plazo. Las bajas parentales y la flexibilización del tiempo de trabajo promueven la inserción laboral de las madres, al tiempo que permiten que los niños/as se beneficien de periodos de cuidado parental. Finalmente, los servicios de cuidado y educación infantil constituyen un nicho de empleo para las mujeres.

En lo que se relaciona con las políticas familiares y de infancia, el Estado social inversor tiene entre sus principales preocupaciones:

- Permitir la conciliación de la vida familiar y la vida laboral, facilitando la incorporación de la mujer al mercado de trabajo y adaptando las políticas sociales a la progresiva desaparición del modelo en el que sólo el hombre trabajaba y sólo la mujer cuidaba (male breadwiner model). Desde ese punto de vista, las políticas familiares serían clave para culminar la "revolución incompleta" ${ }^{3}$ a la que se refiere Esping-Andersen, y que constituye, a su juicio, un factor creciente de desigualdad.

- Favorecer la igualdad de oportunidades en la infancia, rompiendo el ciclo de transmisión intergeneracional de la pobreza, de forma que todos/as los niños/as puedan desarrollar el capital humano imprescindible en la economía del conocimiento. Esto sólo puede lograrse mediante medidas de apoyo a las familias y mediante el

3 Con este término se refiere al proceso mediante el cual las mujeres se han ido incorporando al mercado de trabajo, sin que las estructuras sociales y productivas se hayan adaptado plenamente a ese cambio. Para el autor, mientras las clases más favorecidas han podido, por diversas razones, beneficiarse de ese cambio, y ofrecer a su descendencia unas condiciones adecuadas para su crecimiento, en las clases menos favorecidas el acceso de la mujer al mercado de trabajo ha traído consigo resultados menos efectos positivos. Con las desigualdades en aumento, señala, la capacidad de las familias para invertir en el futuro de sus hijos/as se irá volviendo también más desigual. La herencia social sale reforzada, debido a que la forma en la que las familias invierten en sus hijos/as se caracteriza hoy día por asimetrías sociales cada vez más marcadas. Desde ese punto de vista, la urgencia por culminar esa revolución y de adoptar un cambio de enfoque en las políticas sociales se deriva de la capacidad de generación de desigualdad y de polarización que tiene la situación actual. 
desarrollo de sistemas de educación y cuidado infantil de alta calidad y de amplia cobertura.

Autores como Esping-Andersen, Palier o Morgan defienden el valor que las políticas de apoyo a las familias tienen desde el punto de vista del principio de Pareto, en el sentido de que invertir en la infancia implica no sólo más igualdad, sino también más productividad, de tal forma que todas las partes ganan y ninguna pierde: una mayor equidad va de la mano con una movilización más efectiva de la capacidad productiva y ello trae consigo un mayor desarrollo económico general. El acceso de los niños a las guarderías y a centros prescolares de gran calidad debe, pues, formar parte de una política verdaderamente eficaz en favor de la igualdad de oportunidades si se tiene en cuenta, como señala Esping-Andersen, que las bases del aprendizaje, así como el origen principal de las desigualdades, se remontan al periodo prescolar. En la medida en que el acceso al cuidado de los niños condiciona también el trabajo de las madres -que, a su vez, es portador de efectos de ingresos positivos-, unas medidas que favoreciesen el cuidado de los niños serían un perfecto ejemplo de política doblemente ganadora (Esping-Andersen y Palier, 2010).

Para estos autores, si aspiramos a una sociedad productiva y cohesionada para el futuro, nuestras prioridades políticas han de centrarse en la infancia y la juventud de hoy:

Sólo realizando una inversión sólida en los niños/ as de hoy día se alcanzará el bienestar de los adultos de mañana [...]. Si miramos al futuro, la estrategia más obviamente efectiva desde el punto de vista preventivo es la de invertir fuertemente en los recursos de la infancia hoy. Muchos Estados del Bienestar contemporáneos no están siguiendo esa orientación y, si no se corrigen, pagarán un elevado precio en el futuro.

Desde un punto de vista más concreto, el énfasis de los defensores del Estado social inversor en las políticas de apoyo a las familias o a la infancia se basa en los siguientes argumentos:

- Si bien no está suficientemente probado el efecto de las políticas de apoyo a las familias en las tasas de fecundidad de cada país, resulta evidente que son los países que han desarrollado un mayor esfuerzo en ese ámbito los que registran mayores tasas de fecundidad. Desde ese punto de vista, el desarrollo de unas políticas amplias y eficientes de apoyo a las familias y de conciliación de la familiar y laboral se considera una herramienta imprescindible para garantizar el equilibrio demográfico y, por añadidura, para garantizar la sostenibilidad a medio y largo plazo del Estado de bienestar.

- En la sociedad del conocimiento, las oportunidades vitales de las personas dependen de forma cada vez más acusada del capital cultural, social y cognitivo acumulado desde los primeros años de la infancia. De hecho, para los defensores de este enfoque, las principales formas de desigualdad y las principales fuentes de exclusión provienen en la actualidad de la diferente capacidad de las familias para ofrecer, en los primeros años de vida, los estímulos y aprendizajes necesarios en ese nuevo contexto. Según Esping-Andersen (2002), en efecto, en la sociedad actual las oportunidades siguen estando tan determinadas por la herencia social como en el pasado, y sólo una decidida apuesta por servicios educativos precoces de calidad puede compensar las desigualdades de origen todavía ampliamente vigentes ${ }^{4}$.

Por otro lado, la inversión en el capital humano de la infancia constituye una condición sine qua non para el desarrollo de un sistema productivo sostenible, eficiente y competitivo, acorde a las necesidades de la sociedad del conocimiento: "las naciones que no sean capaces de activar plenamente su potencial humano, quedarán probablemente rezagadas en la carrera de la productividad", señala Esping-Andersen. Para este autor, más aún en las sociedades actuales, las oportunidades vitales de las personas dependen, fundamentalmente, de la capacidad de sus familias, durante la infancia, para dotarlas del capital social, cultural, cognitivo y relacional necesario. A partir de esa idea, sólo un replanteamiento de las políticas sociales que ponga el énfasis en garantizar unas condiciones de vida y un nivel básico de igualdad de oportunidades en la infancia, apoyando de forma decidida a las familias, puede dar respuesta a los retos que para el Estado de bienestar supone la incorporación de la mujer al mercado de trabajo y los cambios producidos en los últimos años en la institución familiar.

- Un tercer argumento se relaciona con el deseo de las familias de tener descendencia y con la necesidad de garantizar que las familias -independientemente de su nivel de rentapuedan tener la descendencia que desean, sin obstaculizar su acceso al mercado de trabajo. Se evitaría de esta forma la creciente polarización entre familias 'pobres' y 'ricas' en trabajo, y la necesidad de optar entre dos situaciones igualmente poco deseables: o pocos hijos/as (fecundidad baja) o poco trabajo y, por tanto, pocos ingresos. Efectivamente, el fracaso a la hora de tratar de conciliar maternidad y vida profesional, señala Esping-Andersen (2010) conducirá a los individuos a arbitrar entre traer hijos al mundo y la búsqueda de un empleo para ganar en autonomía e incrementar los ingresos del hogar.

- Finalmente, se insiste en el carácter preventivo $y$, desde ese punto de vista, coste-efectivo de las políticas de apoyo a la familia, en la medida que han demostrado un alto nivel de retorno económico: el gasto realizado se recupera con creces, a

${ }_{4}^{4}$ Para este autor, sólo en Suecia y, posiblemente, en Dinamarca, se ha podido reducir en los últimos años la influencia de la herencia social en las oportunidades vitales de las personas, debido a la extraordinariamente alta inversión realizada en las políticas sociales para la infancia y para las familias. 
medio plazo, debido fundamentalmente, al ahorro producido al evitarse otros gastos y al garantizarse menores tasas de exclusión y carreras laborales más largas.

\subsection{La relación coste-efectividad de las políticas de apoyo a la infancia}

Los argumentos teóricos señalados en el apartado anterior se apoyan en un número cada vez mayor de estudios empíricos que ponen de manifiesto el positivo efecto que, en términos de coste-eficacia ${ }^{5}$, tiene el gasto social destinado a las políticas familiares. La mayor parte de esos estudios son de origen anglosajón, aunque también se han realizado diferentes investigaciones en Europa, y se centran fundamentalmente en los servicios de atención infantil. Más escasos son, por el contario, los trabajos empíricos orientados a demostrar la relación coste-efectividad de otras políticas de apoyo a las familias, como los permisos parentales o las prestaciones económicas.

Aunque las metodologías y enfoques conceptuales a partir de los que se desarrollan estos estudios no son siempre los mismos, la línea argumental que subyace a todos ellos es similar: el gasto en políticas familiares tiene, para la sociedad, una elevada tasa de retorno en la medida en que:

- Previene, a medio plazo, la necesidad de realizar otros gastos más elevados y menos eficaces, al garantizar una mayor igualdad de oportunidades y la posibilidad de romper el ciclo de transmisión intergeneracional de la pobreza.

- Favorece la inserción laboral de las mujeres, sobre todo las mujeres con menores tasas de cualificación, lo que aumenta la productividad del conjunto de la sociedad.

- Contribuye a aumentar las tasas de fecundidad, dinamizando el tejido social y contribuyendo a la sostenibilidad del conjunto de la protección social.

\subsubsection{La relación coste-beneficio desde el punto de vista preventivo: el efecto mariposa}

Como se ha señalado anteriormente, uno de los argumentos más habitualmente utilizados para demostrar la necesidad de invertir en las políticas de apoyo a la infancia es su carácter preventivo, en contraposición a la naturaleza meramente paliativa que pueden tener otros tipos de gasto social. En ese sentido, para Chau-

${ }^{5}$ De acuerdo a Heckman, Grunewald y Reynolds (2006), el análisis coste-beneficio mide los beneficios de una inversión en relación a sus costes, y se utiliza en el ámbito de la economía para priorizar las inversiones en función de los retornos previstos. En el ámbito de la atención infantil, este enfoque demuestra si los beneficios que estos programas tienen para sus participantes y para el conjunto de la sociedad superan los costes; permite valorar qué tipo de inversión en políticas familiares implica mayores beneficios en relación a los costes generados; y ha demostrado que la inversión en servicios de educación y atención infantil ofrece mayores retornos que otras inversiones en capital humano o en infraestructuras. ffaut (2010), el potencial preventivo de los programas de atención infantil permite hablar de un 'efecto mariposa' en la medida en que numerosos estudios ponen de manifiesto el efecto positivo que supone, a medio y largo plazo, la inversión en servicios de atención infantil de calidad en lo que se refiere a la reducción de los índices de fracaso escolar, las tasas de delincuencia, embarazo adolescente o consumo de sustancias, por ejemplo. Según esta autora:

La mayor parte de los estudios concluyen que existe un retorno positivo en relación a la inversión inicial en los dispositivos de educación precoz, debido al ahorro que se produce a medio plazo en relación a otras políticas públicas, con tasas de retorno que pueden llegar hasta los ocho dólares por cada euro invertido. Dos tercios de ese retorno redundarían en el conjunto de la sociedad y el tercio restante en las propias familias.

Heckman, Grunewald y Reynolds (2006) realizaron una revisión de los resultados que, en términos de coste-eficacia, obtuvieron cuatro programas específicos de atención infantil orientados a niños/as de hasta 4 años de edad. El Cuadro 1 recoge las principales características de esos programas:

Es importante destacar que, en la mayor parte de los casos, los estudios de evaluación de estos programas incluyen la comparación, a largo plazo, de la situación laboral, personal y social de personas con similares características sociodemográficas y similar origen sociofamiliar, que se diferencian únicamente entre sí en el hecho de haber participado o no en su infancia en estos programas. La proyección de los beneficios y retornos que se atribuyen a estos programas se basa en la diferencia existente entre estos dos grupos, una vez llegados a la juventud o a la madurez, en cuanto a inserción laboral, historial delictivo o uso de drogas.

A la hora de realizar la evaluación económica de estos programas, estos autores imputan los principales beneficios a un incremento en los ingresos de los participantes (y en los ingresos fiscales que se derivan de este incremento de ingresos) y al ahorro en el gasto público que se deriva de una reducción en los índices de criminalidad y en la demanda de programas de rehabilitación y tratamiento. Desde el punto de vista del coste-beneficio, la relación entre lo invertido y lo ahorrado es, en todos los casos, superior a 1, y oscila entre los 3,78 dólares por dólar gastado del Carolina Abecedarian Project y los 17 del Perry Preeschool Program. La tasa de retorno ${ }^{6}$, como se observa en la Tabla 1 , oscila entre el $7 \%$ y el $23 \%$ anual.

Al analizar los factores que parecen determinar la rentabilidad de la inversión realizada, Heckman,

${ }^{6}$ Estos autores definen la tasa interna de retorno como la tasa de interés anual que se derivaría de la inversión realizada a lo largo de un número determinado de años. La disponibilidad de este tipo de índices permite valorar qué tipo de inversión pública resulta más rentable. 


\begin{tabular}{|c|c|c|c|}
\hline & Descripción del programa & Diseño de investigación & $\begin{array}{l}\text { Resultados (grupo participante comparado con un } \\
\text { grupo de referencia) }\end{array}$ \\
\hline $\begin{array}{l}\text { Carolina } \\
\text { Abecedarian } \\
\text { Project } \\
\text { (Chapel Hill, NC), } \\
\text { 1972-1977 }\end{array}$ & $\begin{array}{l}\text { Edades objeto de } \\
\text { intervención: desde los } \\
3 \text { meses hasta los } 4 \text { años. } \\
\text { Centro prescolar a jornada } \\
\text { completa. }\end{array}$ & $\begin{array}{l}\text { Asignación de los grupos de } \\
\text { carácter aleatorio. } \\
\text { Grupo de tratamiento de } 57 \text { casos } \\
\text { y el grupo de referencia (control) } \\
\text { de } 54 . \text { La evaluación se realiza } \\
\text { hasta la edad de } 21 \text { años. }\end{array}$ & $\begin{array}{l}\text { Mejores resultados en lectura y matemáticas, tasas } \\
\text { más bajas a la hora de repetir un curso escolar y } \\
\text { recibir educación especial, mayor probabilidad de } \\
\text { matricularse en una carrera universitaria de cuatro } \\
\text { años, mayor probabilidad que las mujeres retrasen la } \\
\text { edad en la que dan a luz a su primer hijo/a. }\end{array}$ \\
\hline $\begin{array}{l}\text { Chicago Child- } \\
\text { Parent Center, } \\
1983-1985\end{array}$ & $\begin{array}{l}\text { Edades objeto de } \\
\text { intervención: desde los } \\
3 \text { hasta los } 4 \text { años. } \\
\text { Centro prescolar, a media } \\
\text { jornada, programa parental } \\
\text { de carácter intensivo. }\end{array}$ & $\begin{array}{l}\text { Diseño cuasi-experimental. } \\
\text { Los } 989 \text { casos del grupo de } \\
\text { tratamiento se comparan con } \\
550 \text { casos seleccionados al azar } \\
\text { en colegios; ambos grupos son } \\
\text { emparejados en función de } \\
\text { variables demográficas. } \\
\text { La evaluación se realiza hasta la } \\
\text { edad de } 21 \text { años. }\end{array}$ & $\begin{array}{l}\text { Mejores resultados en lectura y matemáticas, tasas más } \\
\text { bajas de maltrato infantil, tasas más bajas a la hora de } \\
\text { repetir un curso escolar y recibir educación especial, } \\
\text { mayor probabilidad de matricularse en una carrera } \\
\text { universitaria de cuatro años, ingresos más altos, y tasas } \\
\text { más bajas de arrestos juveniles, condenas judiciales en } \\
\text { la edad adulta e ingresos en prisión. }\end{array}$ \\
\hline $\begin{array}{l}\text { Nurse Family } \\
\text { Partnership: Elmira } \\
\text { Prenatal/Early } \\
\text { Infancy Project } \\
\text { (Elmira, NY), 1978- } \\
1982\end{array}$ & $\begin{array}{l}\text { Edades: desde antes } \\
\text { del nacimiento hasta los } \\
2 \text { años. } \\
\text { Enfermeras colegiadas } \\
\text { proporcionaron } \\
\text { información sobre salud } \\
\text { y sobre cómo ser padres/ } \\
\text { cuidar de los hijos/as a las } \\
\text { madres en sus domicilios. }\end{array}$ & $\begin{array}{l}\text { Asignación de los grupos de } \\
\text { carácter aleatorio: } 116 \text { casos en } \\
\text { el grupo de tratamiento y } 184 \\
\text { en el de referencia (control). La } \\
\text { evaluación se realiza hasta la } \\
\text { edad de } 15 \text { años. }\end{array}$ & $\begin{array}{l}\text { Disminución en las tasas de arresto, de condenas, de } \\
\text { violación de la libertad condicional, y de consumo de } \\
\text { alcohol a la edad de } 15 \text { años; reducción en el gasto } \\
\text { social de los servicios sociales, los malos tratos } \\
\text { infantiles, el consumo de sustancias, las condenas } \\
\text { judiciales a las madres; mayores ingresos para las } \\
\text { madres. }\end{array}$ \\
\hline $\begin{array}{l}\text { High/Scope Perry } \\
\text { Preschool } \\
\text { (Ypsilanti, Mich.), } \\
1962-1967\end{array}$ & $\begin{array}{l}\text { Edades: desde los } 3 \text { hasta } \\
\text { los } 4 \text { años. } \\
\text { Centro prescolar, } 2 \text { horas } \\
\text { y media diarias, una visita } \\
\text { domiciliaria semanal a la } \\
\text { madre. }\end{array}$ & $\begin{array}{l}\text { Asignación de los grupos de } \\
\text { carácter aleatorio: } 58 \text { casos en el } \\
\text { grupo de tratamiento y } 65 \text { casos } \\
\text { en el de referencia (control). } \\
\text { La evaluación se realiza hasta la } \\
\text { edad de } 40 \text { años. }\end{array}$ & $\begin{array}{l}\text { Mejores resultados en lectura y matemáticas, menor } \\
\text { educación especial, mayor probabilidad de alcanzar } \\
\text { estudios superiores, menos arrestos criminales y } \\
\text { meses en prisión, más probabilidad de contar con un } \\
\text { puesto de trabajo y con una vivienda en propiedad, } \\
\text { mayores ingresos, y menor asistencia por parte de los } \\
\text { servicios sociales. }\end{array}$ \\
\hline
\end{tabular}

Nota: Los Child-parent Centers y el proyecto Abecedarian contaban con programas en edad escolar hasta los 7 u 8 años.

Fuente: Heckman, Grunewald y Reynolds (2006).

Tabla 1. Estudios de análisis coste-beneficio en programas de educación temprana por niño (en dólares de 2005)*

\begin{tabular}{|c|c|c|c|c|c|}
\hline & $\begin{array}{l}\text { Coste } \\
\text { medio }\end{array}$ & $\begin{array}{l}\text { Beneficio } \\
\text { medio }\end{array}$ & $\begin{array}{c}\text { Beneficios } \\
\text { netos }\end{array}$ & $\begin{array}{c}\text { Ratio } \\
\text { coste-beneficio }\end{array}$ & $\begin{array}{l}\text { Tasa interna de } \\
\text { retorno (\%) }\end{array}$ \\
\hline Carolina Abecedarian Project & 38.934 & 174.149 & 108.215 & 3,78 a 1 & 7 \\
\hline Chicago Child-Parent Center & 8.018 & 81.399 & 73.381 & 10,15 a 1 & $22^{\star \star}$ \\
\hline $\begin{array}{l}\text { Nurse Family Partnership: Elmira Prenatal/ } \\
\text { Early Infancy Project }\end{array}$ & $7 \cdot 572$ & 38.296 & 30.724 & 5,06 a 1 & $23^{\star \star}$ \\
\hline Perry Preschool & 17.198 & 293.579 & 276.381 & 17.07 a 1 & 18 \\
\hline
\end{tabular}

*Todas las cantidades de dólares en este documento se convirtieron a dólares de 2005 haciendo uso del índice de precios de consumo. **Calculado por Grunewald, los demás datos provienen de estudios. Las tasas internas de devolución para NFP y Chicago son mayores que para Perry, mientras que las ratios coste-beneficio son inferiores, debido al momento en el que tuvieron lugar los beneficios fruto del tratamiento. Fuente: Heckman, Grunewald y Reynolds (2006).

Grunewald y Reynolds insisten en la intensidad de la atención prestada y en la integralidad de la intervención, así como en la elevada cualificación y en las adecuadas condiciones laborales de los profesionales.

Otro de los estudios que habitualmente se cita a la hora de argumentar la relación coste- efectividad de los programas de atención infantil es el informe que Karoly y Bigelow realizaron en 2005 para la Rand Corporation sobre la educación prescolar en California. De acuerdo a este estudio, si el $25 \%$ de los niños/ as menos favorecidos de California se beneficiaran de al menos un año de educación prescolar, se obtendría una ganancia de al menos dos dólares por cada dólar gastado. El ahorro inducido por el gasto en educación prescolar provendría de la reducción en las tasas de fracaso escolar, una mayor tasa de acceso a la educación secundaria, menores índices de delincuencia y un incremento de los salarios. Para los niños/as de las clases menos desfavorecidas, los retornos serían todavía mayores y oscilarían entre los 2,62 y los 4 euros por cada euro invertido (Chauffaut, 2010). Para los autores del informe, si se garantizara una tasa de participación del $70 \%$ en un programa universal de educación prescolar, cada cohorte de niños/as californianos/as atendida generaría un beneficio de 2.700 millones de dólares, que, una vez sumados los impuestos y cotizaciones generados por ese gasto, alcanzarían los 3.600 millones: según sus cálculos 
-derivados del efecto real del programa experimental-, el beneficio para la sociedad californiana de este tipo de programas ascendería a 11.400 dólares por cada niño/a atendido/a, frente a un coste de 4.339 dólares, lo que supone un ahorro neto de 7.036 dólares por participante (2,62 dólares de beneficio por cada dólar invertido). Ello implicaría una tasa de retorno anual del $10 \%$ para la sociedad californiana, durante sesenta años, de la inversión realizada.

\subsubsection{La importancia de la intervención precoz}

La mayor parte de los estudios empíricos y de las reflexiones teóricas desarrolladas en torno al carácter coste-efectivo de los programas de apoyo a la infancia y a las familias insisten en la necesidad de focalizar los esfuerzos, y el gasto, en la primera infancia. Esping-Andersen recuerda en ese sentido que las políticas paliativas dirigidas a la población adulta son una alternativa pobre, y costosa, a las intervenciones preventivas desarrolladas durante la infancia. En la medida en que las perspectivas de inserción laboral de una persona dependen, de forma creciente, de sus capacidades cognitivas, es en la infancia más precoz -allí donde estas se desarrollan- la etapa en la que resulta más oportuno centrar los esfuerzos. El argumento parte de la idea de que las bases cognitivas decisivas quedan fijadas en el curso de la primera infancia y de que lo que ha tenido lugar en la etapa prescolar es fundamental para la motivación y las capacidades de aprendizaje del niño o niña una vez ha entrado en la escuela. Los orígenes sociales, pues, nos han marcado ya profundamente antes de que el Estado del bienestar intervenga de verdad en nuestras vidas (Esping-Andersen y Palier, 2010). De acuerdo con estos autores:

En materia de herencia social los mecanismos que cuentan realmente hay que buscarlos en la etapa prescolar. Para muchos niños se trata también del periodo en que están más 'privatizados', cuando dependen casi exclusivamente de la familia. De hecho, como pueden confirmar casi todos los profesores desde el primer día de clase, los niños llegan a la escuela muy desigualmente preparados. La escuela y, más en general, el sistema educativo están intrínsecamente poco equipados para anular tales distancias; además, son muy numerosos los estudios que nos muestran cómo las políticas destinadas a poner remedio a la situación son relativamente ineficaces. Todo ello sugiere de nuevo un punto crucial. Tanto si nuestro objetivo es crear más igualdad como si se trata simplemente de aumentar la productividad de la fuerza de trabajo del mañana, debemos concentrar el análisis en lo que sucede entre las cuatro paredes del domicilio familiar. Es allá donde se sitúan los efectos realmente importantes.

En ese sentido, J. Heckman, uno de los principales impulsores de esta línea de investigación, relaciona la necesidad de centrar la inversión en los primeros años de vida con la dinámica de la formación de las habilidades del ser humano. A su juicio, la neurociencia y la psicología experimental han demostrado que los primeros años de edad son críticos para el aprendizaje, tanto desde el punto de vista cognitivo como no cognitivo. El aprendizaje, señala, es un proceso dinámico en el que los aprendizajes precoces refuerzan los aprendizajes posteriores. Las implicaciones del aprendizaje precoz para el desarrollo del capital humano son claras, señala Heckman: el momento óptimo para una intervención productiva, el momento óptimo para invertir, es cuando los niños/as son muy pequeños.

Así, los datos de este autor ponen de manifiesto que las intervenciones resultan tanto más rentables o coste-beneficiosas cuanto antes se desarrollen. En un artículo ampliamente citado (Heckman, 2006), este autor compara las tasas de retorno de diferentes tipos de intervención: prescolar, escolar y postescolar. Mientras los programas desarrollados durante la etapa prescolar obtienen una ratio de retorno superior a uno (el beneficio es superior al gasto), los programas aplicados en la escuela y los de formación profesional no alcanzan ese nivel; pueden resultar beneficiosos, en el sentido de obtener resultados positivos, pero el coste que requieren resulta superior, en términos económicos, a los beneficios obtenidos. La conclusión de este autor es clara: la compensación tardía de un contexto familiar deficitario resulta muy costosa. Si la sociedad espera demasiado para compensar esos déficits, la inversión nunca podrá resultar efectiva.

\section{Gráfico 1. Tasas de retorno en inversión en capital humano}

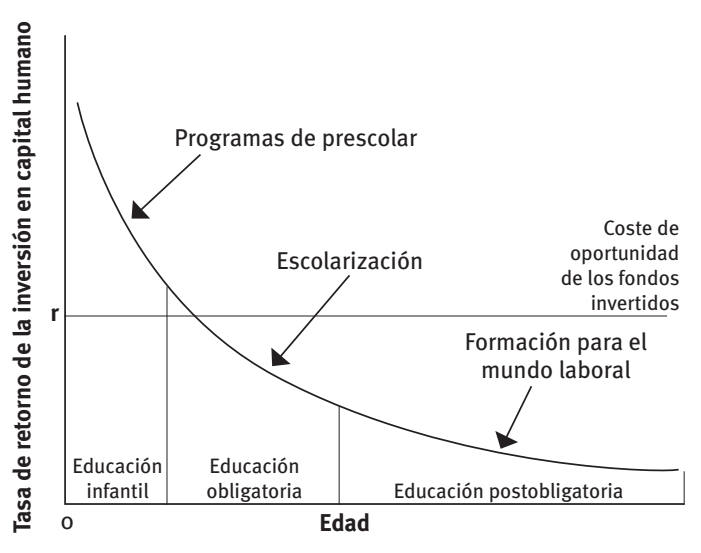

Fuente: Heckman (2006). La traducción es nuestra

\subsubsection{El retorno de los cuidados infantiles desde el punto de vista del mantenimiento de la actividad laboral de las madres}

La perspectiva europea no se ha centrado tanto en el retorno que se deriva de la prevención de conductas o problemas que generan después un coste elevado, sino en valorar las consecuencias económicas que tienen los servicios de apoyo a las familias en la 
medida en que permiten la conciliación laboral y el mantenimiento de la vinculación entre las madres y el mercado laboral.

Desde ese punto de partida, Esping-Andersen (2010) ha planteado -en términos teóricos- las consecuencias que, para las arcas públicas danesas, podría tener la inversión realizada por el Estado al financiar el coste de atención infantil y escolarización de una mujer trabajadora. El análisis está realizado en relación al caso de una mujer de 30 años con dos hijos. Su salario representa el $67 \%$ del salario medio y, gracias a los servicios de atención infantil, no deja de trabajar hasta jubilarse a los 60 años, salvo un año de permiso de maternidad. Según los cálculos del autor, el gasto público asciende a unos 72.000 euros (dos años de guardería y tres de educación infantil, multiplicados por dos hijos/as). Como consecuencia de la extensión de su carrera laboral, la madre en cuestión recibe unas ganancias adicionales de 314.000 euros a lo largo de toda su vida por no haber dejado de trabajar. A su vez, las administraciones ingresan 110.000 euros (casi el 33\%) debido a ese incremento de renta. A largo plazo, la Administración obtiene un beneficio de 37.000 euros por la inversión realizada: es decir, recupera el gasto inicial y obtiene un rendimiento del $50 \%$.

\begin{tabular}{|c|c|}
\hline $\begin{array}{l}\text { Cuadro 2. Contabilidad dinámica de los costes e i } \\
\text { sobre la inversión resultante de modos de cuida } \\
\text { de la familia }\end{array}$ & $\begin{array}{l}\text { gresos } \\
\text { o fuera }\end{array}$ \\
\hline $\begin{array}{l}\text { Hipótesis } \\
\text { - Una mujer de } 30-35 \text { años tiene dos hijos. } \\
\text { - No deja de trabajar, excepto un permiso de matern } \\
\text { un año. } \\
\text { - Su salario representa el } 67 \% \text { del salario medio. } \\
\text { - Sigue trabajando hasta los } 60 \text { años. }\end{array}$ & dad de \\
\hline Coste público & $€$ \\
\hline a) Dos años en guardería (x 2) & 24.000 \\
\hline b) Tres años en prescolar ( $x$ 2) & 48.850 \\
\hline Total & 72.850 \\
\hline Ganancias para la madre & $€$ \\
\hline 5 años de ingresos completos & $114 \cdot 300$ \\
\hline $\begin{array}{l}\text { Las ganancias de sueldo de toda una vida por no } \\
\text { haber interrumpido }\end{array}$ & 200.100 \\
\hline Total & 314.400 \\
\hline Ganancias de Hacienda & $€$ \\
\hline Ingresos adicionales por (a) & 40.000 \\
\hline Ingresos adicionales por (b) & 70.000 \\
\hline Total & 110.000 \\
\hline $\begin{array}{l}\text { Retorno neto a Hacienda sobre la inversión original } \\
(110.000-72.850)\end{array}$ & 37.150 \\
\hline
\end{tabular}

Fuente: Esping-Andersen y Palier, 2010.

Según el autor, "a grandes rasgos, una madre que deja de trabajar durante cinco años para ocuparse de sus hijos ganará en el curso de su vida un $40 \%$ menos que si no se hubiese detenido. Cosa que, naturalmente, implica también que el Estado percibirá menos impuestos durante ese periodo. A partir de los cálculos referidos al caso danés, estimo que las mujeres que se benefician de un sistema de cuidado subvencionado acaban, a largo plazo, por rembolsar (¡con intereses!) la subvención inicial gracias al incremento de sus ganancias a escala de una vida y a los impuestos que se derivan" (EspingAndersen, 2010).

Desde un punto de vista más empírico, un estudio publicado por Chauffaut (2010) recoge los resultados de diversas investigaciones centradas en el retorno que, en términos de incremento de la productividad y mantenimiento de la vinculación de las madres con el mercado de trabajo, alcanzan los servicios de atención infantil en Europa. Los datos de los diferentes estudios no son obviamente homogéneos, pero apuntan en todo caso a una misma dirección:

- La disponibilidad de una plaza en guardería incrementa en un $15 \%$ la probabilidad de que una madre permanezca activa, lo que los investigadores cuantifican en un beneficio anual de 6.000 euros, que representa en torno al tercio del coste de la plaza (Maurin y Roi, 2008).

- Otro estudio (Bayet, 1997) estima en 13.500 euros la ganancia media de cada trabajadora, en el conjunto de su vida laboral, por cada año de guardería de sus hijos/as. Según ese estudio, las mujeres que interrumpen su actividad laboral para hacerse cargo de sus hijos/as incurren en una pérdida de ingresos de al menos el $1 \%$ anual, lo que durante una carrera de 30 años, supone

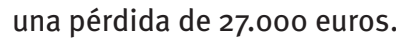

- Un estudio realizado en Suiza (Kucera y Bauer, 2001) indica que una inversión anual de 18 millones de francos suizos en servicios de infancia se compensa con ahorros de 29 millones en gastos fiscales y asistenciales, al multiplicar por dos la tasa horaria de actividad de las familias monoparentales.

- Desde una perspectiva de naturaleza también macroeconómica, un trabajo de Meda y Perivier (2007) estima que una política de apoyo a las familias adecuada desde el punto de vista de la efectividad y de la equidad de género supondría un coste del $1,65 \%$ del PIB, frente al 1,32\% que en la época destinaba Francia a esta cuestión. Esta inversión provocaría el acceso al mercado de trabajo de unas 450.000 mujeres, que, en el caso de tener una productividad media, implicaría un crecimiento del PIB de 1,6 puntos y una reducción de los gastos de protección social de 0,2\% del PIB.

Para Esping-Andersen (2010), “la lógica que subyace en este análisis de los costes y los beneficios es muy convincente, pues integra los efectos de sinergia positiva (el aprendizaje engendra aprendizaje) que las inversiones precoces ejercen sobre el coste de las inversiones ulteriores. El 'rendimiento' aumenta de forma tanto más importante (para llegar a ser exponencial) cuanto más pequeño es el niño atendido, cosa que sugiere que las actuaciones realizadas 
antes de la entrada en la escuela y al inicio de la escolaridad implican beneficios netos muy elevados, más que proporcionales. Si el beneficio estándar sobre las inversiones en los estudios gira alrededor del $10 \%$, se puede anticipar que los beneficios sobre inversión prescolar podrán llegar al doble de este nivel. Y si los rendimientos marginales son claramente más elevados para quienes corren más peligro de fracasar en la escuela, las inversiones precoces deberían de permitir una homogeneización social hacia arriba y una ganancia en términos de igualdad de oportunidades".

\section{Las políticas de apoyo a las familias de la CAPV en una perspectiva comparada}

\subsection{Introducción}

Si bien en el informe original la comparación de las políticas de apoyo a las familias de la CAPV con la que se realiza en otros países de la UE y en otras comunidades autónomas del Estado español se ha realizado desde dos puntos de vista -el del gasto destinado a estas políticas, por una parte, y el del contenido de esas prestaciones, por otra-, el presente artículo se centra de forma preferente en el análisis desde el punto de vista del gasto. Con todo, en el apartado de conclusiones se ofrecen las principales diferencias que existen en relación al contenido de las ayudas existentes en la CAPV y en los países analizados.

Por otra parte, es importante recordar, como se ha señalado en la introducción, que no se hace referencia en este informe a la forma en la que se financian estas ayudas -mediante impuestos generales, impuestos finalistas o cotizaciones a la Seguridad Social-, ni al nivel de la Administración al que corresponde su prestación. Ese análisis resultaría interesante a la hora de determinar a la acción o inacción de qué niveles administrativos cabe atribuir el déficit de gasto que en este ámbito registra la CAPV, pero queda fuera de las posibilidades de este artículo.

Tal y como se ha señalado en el apartado introductorio, tampoco se tienen en cuenta en este repaso - o se tiene sólo en cuenta de forma muy puntual- la existencia de servicios o prestaciones económicas que no corresponden estrictamente al ámbito de las prestaciones de apoyo a las familias, sino a otros ámbitos de la protección social, como la educación?, la vivienda, la salud, los servicios sociales o las prestaciones de garantía de ingresos. No se hace referencia, por tanto, a medidas relacionadas con las becas y ayudas escolares, las prestaciones para la educación especial de niños/as con discapacidad, los posibles suplementos en las prestaciones de garantía de ingresos en el caso de las familias monoparentales, o las ayudas a la vivienda dependientes del tamaño

7 Salvo, como ya se ha indicado, la educación infantil previa a la educación primaria. o la estructura familiar. En el caso de los países europeos, tampoco se tienen en cuenta las prestaciones de ámbito regional o municipal que puedan existir.

Para entender las conclusiones que se derivan de este informe, en cualquier caso, es necesario tener en cuenta las limitaciones de las comparaciones internacionales relativas al gasto en servicios públicos. Al margen de eventuales diferencias en la metodología seguida por cada instituto estadístico para la recogida de sus datos, las limitaciones se refieren fundamentalmente a que comparar un tipo de servicios o prestaciones -educativas, de salud, de servicios sociales, de vivienda, de apoyo a la familia, por poner algunos ejemplos- de forma aislada impide recoger los efectos del conjunto de las políticas públicas sobre el bienestar de las familias o su nivel de eficacia, y ofrece, por tanto, una imagen necesariamente parcial de la realidad que se quiere comparar.

Un buen ejemplo de esa limitación es la no consideración en este informe del gasto en el ámbito de las rentas de garantía de ingresos. Por una parte, la decisión de no incluir este tipo de prestaciones en la comparativa es razonable, porque no se trata, estrictamente hablando, de ayudas a las familias y porque, en las fuentes estadísticas internacionales utilizadas, las prestaciones económicas de garantía de ingresos se diferencian de las políticas y prestaciones familiares. Pero por otra parte, qué duda cabe, se trata de prestaciones económicas que benefician directamente las familias y, en concreto, a las familias en situación de pobreza o en riesgo de exclusión. La no inclusión de este tipo de prestaciones en la comparativa tiene un efecto importante en los resultados, puesto que constituyen, en Euskadi, una fuente fundamental de apoyo a las familias en situación de pobreza o exclusión. En ese sentido, es necesario destacar el componente de protección a los menores en situación de pobreza y exclusión del sistema de rentas mínimas establecido en la CAPV: en 2012 el número de menores de 16 años pertenecientes a familias perceptoras de la renta de garantía de ingresos (RGI) era de 24.370, que representan en torno al $8 \%$ de los menores de esa edad en Euskadi. En total, el $27 \%$ de las familias perceptoras tienen a su cargo a menores de 16 años, y se destina a ellas un gasto que ronda los 156 millones de euros, que representan en torno al $40 \%$ de todo el gasto en renta de garantía de ingresos.

\subsection{El gasto social en las políticas de apoyo a las familias}

\subsubsection{Aclaraciones metodológicas}

Como se ha señalado previamente, para analizar el gasto destinado a las políticas de atención a las familias se han utilizado básicamente dos fuentes de datos, la Cuenta de la Protección Social de Eustat y el Sistema Europeo de Estadísticas Integradas de Protección Social (SEEPROS) de Eurostat, que utilizan la misma metodología. Estas estadísticas 
recogen todo el gasto realizado en el ámbito de lo que tradicionalmente se ha considerado como protección social, salvo en el ámbito de la educación. La estadística divide el gasto en ocho funciones o áreas: vejez, enfermedad/atención sanitaria, invalidez, desempleo, supervivencia, vivienda, exclusión social, y familia e hijos/as. Además de estas cuestiones, en una fase posterior, se ha añadido, a partir de las estadísticas europeas y de los datos de Eustat sobre gasto en educación infantil, el gasto que a nivel de la CAPV, del Estado español y de la UE se realiza en la educación infantil de o a 6 años ${ }^{8}$.

Aunque se trata, sin duda, de la única forma de comparar de forma homogénea el gasto en protección social que se realiza en países diferentes, su uso plantea ciertas dificultades:

- La atribución de determinados gastos a determinadas funciones puede no siempre realizarse siguiendo los mismos criterios. Efectivamente, como se explica en la nota metodológica del final del artículo, Eustat imputa una parte de los gastos correspondientes a las ayudas del Gobierno Vasco a las familias con hijos e hijas a la función de exclusión social, y no a la de familia, lo que supone una reducción importante del gasto total destinado a esa función y tenido en cuenta para este estudio. Por ello, para la redacción de este informe ese criterio ha sido modificado, imputando ese gasto a la función de familia, si bien no debe descartarse la posibilidad de que existan más anomalías de este tipo.

- Los últimos datos que ofrece Eustat, a noviembre de 2012, sobre el gasto en protección social corresponden al año 2008, lo que implica un cierto desfase de los datos ofrecidos en relación a la situación actual. Los últimos datos relativos a la educación infantil se refieren, por su parte, a 2007.
- Los datos de Eustat y de Eurostat no desagregan de la misma forma los niveles institucionales responsables de los diversos gastos, lo que impide realizar comparaciones adecuadas entre el gasto realizado a nivel europeo y de la CAPV por el sistema de la Seguridad Social y el de los servicios sociales, o por las administraciones centrales, regionales o municipales.

- Especialmente en lo que se refiere a las prestaciones en especie, se incluyen en este ámbito prestaciones no estrictamente imputables a las políticas de apoyo a las familias, como pueden ser los acogimientos residenciales de menores de edad en situación de desprotección.

\subsubsection{Un incremento importante del gasto como consecuencia del impulso a las políticas de apoyo a las familias realizado por el Gobierno Vasco}

Si se tiene en cuenta únicamente el gasto en la función familia e hijos que recoge la Cuenta de la Protección Social de Eustat, se observa claramente el importante crecimiento que han experimentado las ayudas a la familia desde mediados de los años noventa en Euskadi. En 2008, el gasto en la función familia e hijos/as realizado en la CAPV alcanza los 368 millones de euros, o, en otros términos, los 172 euros por habitante. El gasto en la función de familia e hijos/as representa el 0,54\% del PIB y el $2,76 \%$ del gasto en el conjunto de la protección social. Cabe

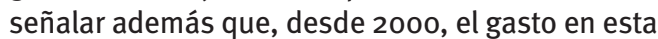
materia se ha triplicado en términos de euros corrientes, mientras que el esfuerzo en relación al PIB prácticamente se ha duplicado, con un incremento particularmente intenso del gasto a partir del año 2005.

Junto al ya señalado incremento del gasto, uno de los cambios más notables que se ha producido en este

Tabla 2. Evolución del gasto en familia/hijos. CAPV, 1995-2008 (en millones de euros, euros/habitante, \% del PIB y $\%$ del gasto en protección social)

\begin{tabular}{|c|c|c|c|c|c|c|c|c|c|c|c|c|}
\hline & 1995 & 1997 & 1999 & 2000 & 2001 & 2002 & 2003 & 2004 & 2005 & 2006 & 2007 & 2008 \\
\hline $\begin{array}{l}\text { Millones de } \\
\text { euros }\end{array}$ & 63,9 & 83,6 & 99,5 & 110,2 & 130,4 & 137,5 & 156,3 & 168,1 & 201,6 & 249,7 & 305,2 & 368,0 \\
\hline Euros/hab. & 30,0 & 39,8 & 47,4 & 52,5 & 62,1 & 65,5 & 74,4 & 79,7 & 95,5 & 118,0 & 143,6 & 172,5 \\
\hline$\%$ del PIB & 0,22 & 0,26 & 0,26 & 0,26 & 0,30 & 0,30 & 0,32 & 0,32 & 0,35 & 0,40 & 0,46 & 0,54 \\
\hline $\begin{array}{l}\text { \% del gasto } \\
\text { en protección } \\
\text { social }\end{array}$ & 1,15 & 1,35 & 1,47 & 1,50 & 1,63 & 1,60 & 1,69 & 1,70 & 1,89 & 2,20 & 2,49 & 2,76 \\
\hline
\end{tabular}

Fuente: Cuenta de la Protección Social de Eustat.

${ }^{8}$ Como se explica en la nota metodológica del final del artículo, para no computar dos veces el mismo gasto, al añadir el gasto en educación infantil recogido de la Cuenta de la Educación se ha eliminado del cómputo el gasto en guarderías que recoge la Cuenta de la Protección Social, ya que tanto Eustat como el Ministerio de Sanidad, Servicios Sociales e Igualdad (responsable del sistema SEEPROS en España) incluyen este segundo gasto a la hora de calcular la financiación de la educación infantil. 
periodo es la reducción del peso del gasto financiado por la Seguridad Social, y el incremento del gasto que financian otros sistemas de protección social $\mathrm{y}$, particularmente, el sistema de servicios sociales. Así, si en 1995 casi dos terceras partes del gasto en la función familia venían determinadas desde el sistema de Seguridad Social, en 2008 ese porcentaje no llegaba al $50 \%$. Entre 2000 y 2008 , el gasto de las instituciones no englobadas en el sistema de la Seguridad Social creció un $454 \%$, mientras que el financiado por la Seguridad Social hizo en un $254 \%$. Un 60\% del incremento del gasto experimentado entre 2000 y 2008 se explica por el crecimiento del gasto financiado por otras instituciones, mientras que el $40 \%$ restante vendría financiado desde la Seguridad Social.

Es importante señalar, en cualquier caso, que la estadística SEEPROS tiende a subestimar el gasto en la función de familia e hijos/as al incluir en la función de exclusión social una parte de las ayudas económicas que las instituciones vascas, y especialmente el Gobierno Vasco, han venido concediendo a las familias con hijos/as. La Tabla 3 recoge una versión corregida de la Cuenta de la Protección Social, incluyendo además del gasto ya recogido en las tablas anteriores para los años posteriores a 2002, el gasto que según el Estudio sobre Gasto Público en Servicios Sociales se destina a las ayudas económicas a las familias con hijos/as. Se trata de una cantidad importante (38 millones de euros en 2008), con lo que el gasto total pasa de 368 a 406,2 millones.
Como consecuencia de esta corrección, el panorama cambia de forma relativamente importante. El gasto alcanza el $0,60 \%$ del PIB y el gasto por habitante pasa a 188 euros, frente a los 172 estimados inicialmente. En relación al conjunto de la protección social, el gasto en familia representaría el 3,05\% del total. También cambia el porcentaje del gasto no atribuible a la Seguridad Social, cuya pérdida de peso es todavía más evidente. De hecho, a partir de 2005 el gasto de la Seguridad Social comienza a ser superado por el que realizan las demás instituciones.

\begin{tabular}{|c|c|c|c|c|c|c|c|}
\hline & 2002 & 2003 & 2004 & 2005 & 2006 & 2007 & 2008 \\
\hline $\begin{array}{l}\text { Millones } \\
\text { de euros }\end{array}$ & 154,1 & 176,4 & 190,6 & 225,3 & 279,7 & 341,0 & 406,2 \\
\hline Euros/hab. & 73,1 & 83,5 & 90,1 & 106,0 & 131,1 & 159,2 & 188,3 \\
\hline$\%$ del PIB & 0,33 & 0,36 & 0,36 & 0,39 & 0,45 & 0,51 & 0,60 \\
\hline $\begin{array}{l}\% \text { del } \\
\text { gasto en } \\
\text { protección } \\
\text { social }\end{array}$ & 1,80 & 1,91 & 1,92 & 2,12 & 2,46 & 2,78 & 3,05 \\
\hline
\end{tabular}

Fuente: Cuenta de la Protección Social de Eustat.

\section{Gráfico 2. Evolución de la distribución del gasto en familia, por sistemas. CAPV, 1995-2008 (\%)}

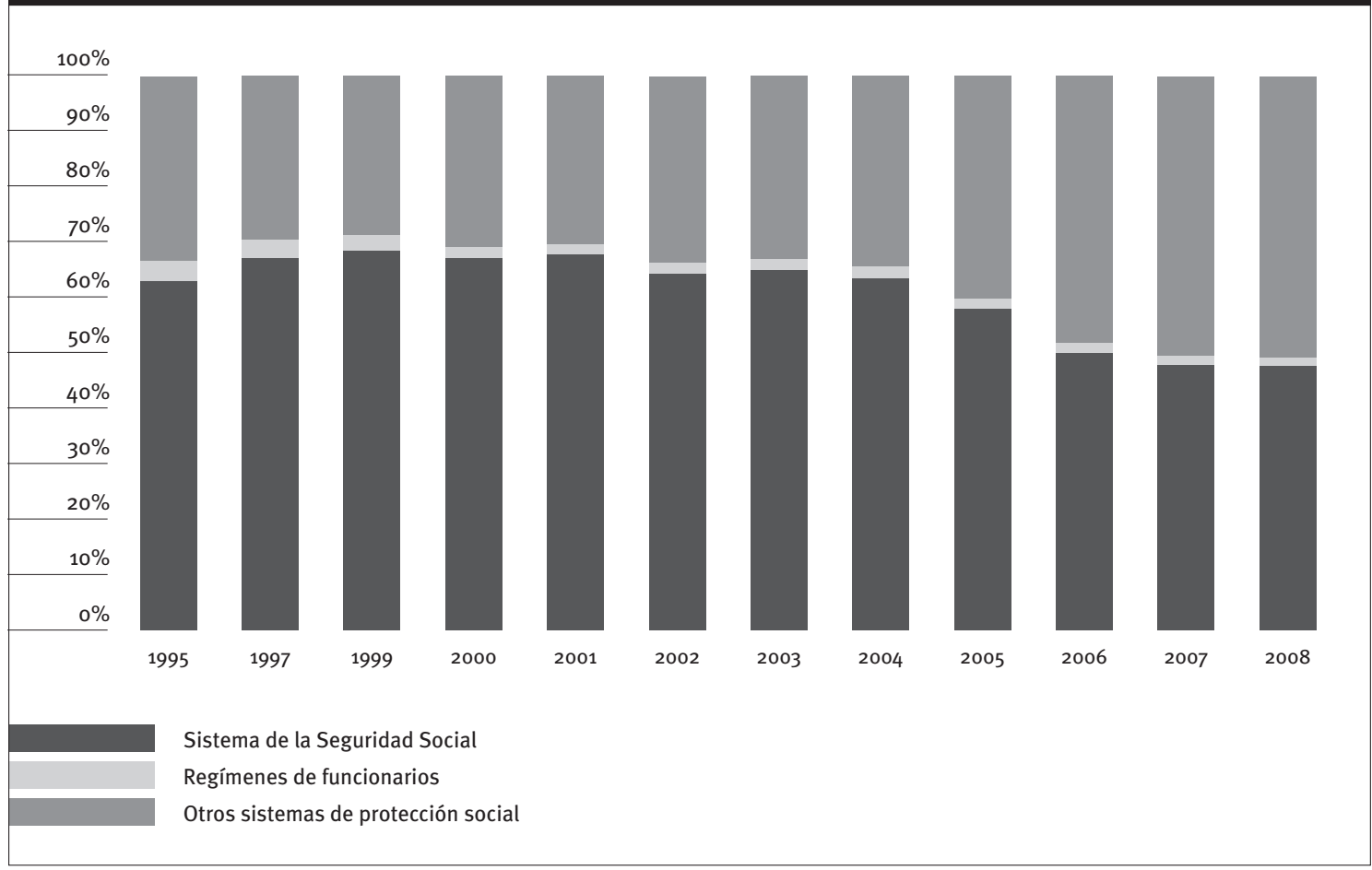

Fuente: Elaboración propia a partir de la cuenta de la Protección Social de Eustat. 


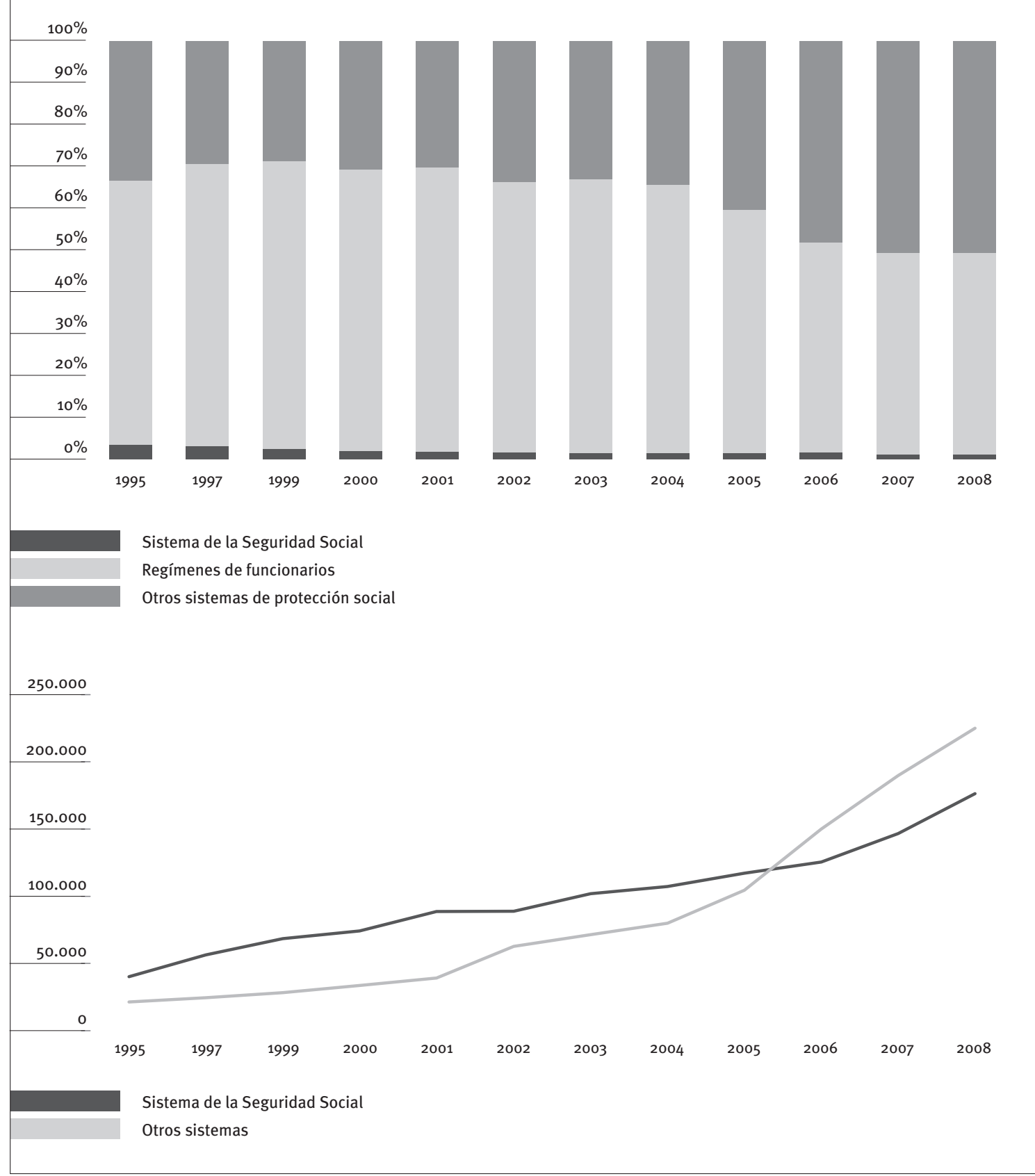

Fuente: Elaboración propia a partir de la cuenta de la Protección Social de Eustat.

\subsubsection{El peso de los servicios de atención infantil en el conjunto del gasto en políticas de apoyo a las familias}

A la hora de tener en cuenta el gasto de las administraciones en las políticas de apoyo a las familias es necesario, en cualquier caso, tener también en cuenta el gasto que se realiza en lo que se refiere a la educación no obligatoria, es decir, la etapa de educación infantil o preprimaria qua va de los o a los 6 años. La disponibilidad de datos estadísticos sobre esta cuestión es menor para la CAPV, ya que la
Cuenta de la Educación -que incluye esta partidasólo ofrece datos de gasto en educación infantil para los años 2001 y 2007. El resto de las estadísticas disponibles no diferencian entre el gasto en educación infantil y en educación primaria, que, por su carácter obligatorio, no parece conveniente tener en cuenta a la hora de analizar las políticas de apoyo a las familias. Las dificultades metodológicas se incrementan si se tiene en cuenta que una parte del gasto en educación infantil está ya recogido en la cuenta de la protección social (SEEPROS). Ello obliga, para tener en cuenta el conjunto del gasto, a eliminar las 
partidas duplicadas, de forma que el gasto total no se compute dos veces.

Teniendo estas aclaraciones metodológicas en cuenta, la Tabla 4 recoge para 2007, el conjunto del gasto realizado en la función familia e hijos y en educación infantil no obligatoria de o a 6 años. Como se observa en ella, el gasto total asciende a 662 millones de euros, que representan el $1 \%$ del PIB o 2.076 euros por persona menor de edad residente en Euskadi. Se observa, además, que el gasto en educación infantil representa la mayor parte del gasto (un $66 \%$ ), frente al $33 \%$ de las prestaciones económicas.

\subsubsection{Un gasto inferior al que se realiza en los países de Europa pero superior, en términos de gasto por persona menor de edad, al que se realiza en el conjunto del Estado español}

Una vez calculado el gasto total que las instituciones vascas destinan a las políticas de apoyo a las familias, el gasto resultante se ha comparado -utilizando la misma metodología- con el que se realiza en otros países de nuestro entorno y en el conjunto del Estado español. El análisis realizado pone de manifiesto que, en términos de gasto por persona menor de edad, el gasto que se realiza en Euskadi en políticas de apoyo a las familias es superior al que se realiza en el conjunto del Estado. Sin embargo, si el gasto se mide en relación al PIB, resulta inferior al estatal y mucho más bajo que el que se realiza en los países de Europa analizados.

Efectivamente, si el gasto en la función familia realizado en 2007 en Euskadi y en el conjunto del Estado español se plantea en términos de gasto por cada per- sona menor de edad residente en cada ámbito territorial, se observa que el gasto vasco es un $10 \%$ superior al del conjunto del Estado. Así, en España el gasto en políticas de apoyo a las familias asciende a 1.859 euros por menor, mientras que en la CAPV el gasto es de $\mathbf{2 . 0 7 6}$ euros por cada persona menor de edad. Las principales diferencias se dan en lo que se refiere a las prestaciones económicas de mantenimiento de rentas en caso de maternidad (ya que se incluyen en ese capítulo las ayudas económicas a la conciliación que otorga el Gobierno Vasco), y en lo que se refiere a la educación infantil de o a 6 años, puesto que la CAPV destina un gasto un $30 \%$ superior, por menor, a este servicio. También es más importante el gasto vasco en subsidios a la natalidad -con un gasto de 132 euros por menor, frente a 75 en el conjunto del Estado-, ya que en ellos se integran las prestaciones económicas por nacimiento e hijo/a a cargo que otorga el Departamento de Empleo y Asuntos Sociales del Gobierno Vasco. Destaca por último, en el caso estatal, el elevado gasto que se asigna al epígrafe de 'otras prestaciones' -tanto en efectivo como en especie-, frente al reducido gasto imputado a este tipo de prestaciones genéricas en la CAPV.

En términos de gasto en relación al PIB, sin embargo, el gasto que realiza la CAPV es menor en todas las partidas, incluyendo la educación infantil (debido tanto al mayor PIB por habitante vasco como al hecho de que la proporción de menores de edad sea en el Estado mayor que en la CAPV, lo que lógicamente impulsa el gasto al alza): Euskadi destina a estas prestaciones un $1 \%$ del PIB, frente al 1,38\% del conjunto del Estado. En el caso de la educación infantil, el esfuerzo en ambos territorios es similar (0,56\% y 0,59\%), así como en lo que se refiere a los subsidios a la natalidad, mientras que en el caso de la asignación por hijo a cargo las diferencias resultan más evidentes.

Tabla 4. Gasto total en políticas de apoyo a las familias. CAPV, 2007 (en miles de euros, euros por habitante, \% del PIB y \% del gasto en protección social)

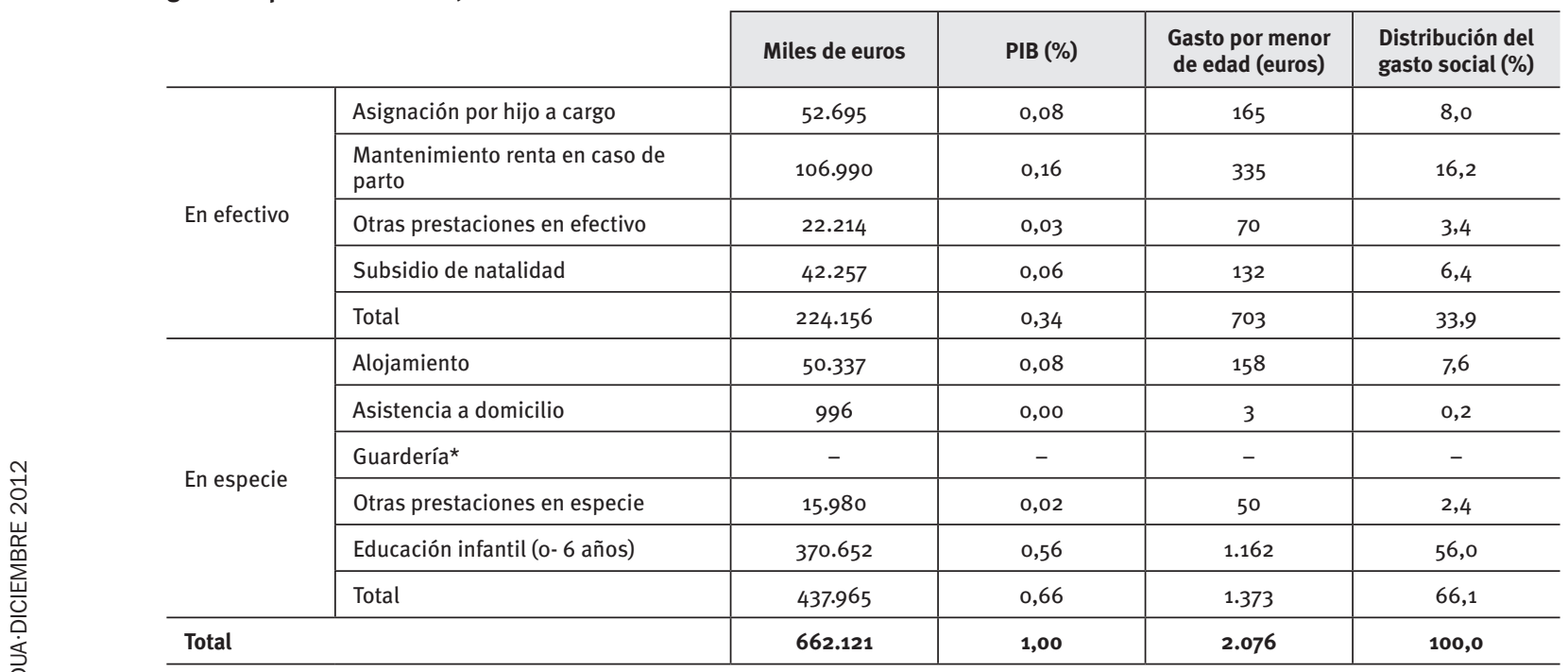

*El gasto SEEPROS en guarderías no se tiene en cuenta, debido a que se incluye dentro del gasto en educación infantil

Fuente: Elaboración propia a partir de la Cuenta de la Protección Social y la Cuenta de la Educación de Eustat. 
Tabla 5. Gasto total en políticas de apoyo a las familias. CAPV y España, 2007 (en \% del PIB y por persona menor de edad)

\begin{tabular}{|c|c|c|c|c|c|}
\hline & & \multicolumn{2}{|c|}{ CAPV } & \multicolumn{2}{|c|}{ España } \\
\hline & & PIB (\%) & $\begin{array}{l}\text { Menor de edad } \\
\quad \text { (euros) }\end{array}$ & PIB (\%) & Menor de edad \\
\hline \multirow{5}{*}{ En efectivo } & Asignación por hijo a cargo & 0,08 & 165 & 0,17 & 231 \\
\hline & Mantenimiento renta en caso de parto & 0,16 & 335 & 0,17 & 223 \\
\hline & Otras prestaciones en efectivo & 0,03 & 70 & 0,14 & 190 \\
\hline & Subsidio de natalidad & 0,06 & 132 & 0,06 & 75 \\
\hline & Total efectivo & 0,34 & 703 & 0,54 & 719 \\
\hline \multirow{6}{*}{ En especie } & Alojamiento & 0,08 & 158 & 0,09 & 117 \\
\hline & Asistencia a domicilio & 0,00 & 3 & 0,00 & 5 \\
\hline & Guardería* & - & - & - & - \\
\hline & Otras prestaciones en especie & 0,02 & 50 & 0,17 & 226 \\
\hline & Educación infantil (o- 6 años) & 0,56 & 1.162 & 0,59 & 792 \\
\hline & Total & 0,66 & 1.373 & 0,85 & 1.140 \\
\hline Total & & 1,00 & 2.076 & 1,38 & 1.859 \\
\hline
\end{tabular}

*El gasto SEEPROS en guarderías no se tiene en cuenta debido a que se incluye dentro del gasto en educación infantil.

Fuente: Elaboración propia a partir de la Cuenta de la Protección Social y la Cuenta de la Educación de Eustat, Eurostat y Cuentas Integradas sobre Protección Social del Ministerio de Empleo y Seguridad Social.

En cualquier caso, a la hora de interpretar el hecho de que el gasto estatal sea, en relación al PIB, superior al vasco es importante tener en cuenta, en primer lugar, como ya se ha dicho, el hecho de que el PIB por habitante es sustancialmente mayor en Euskadi que en el Estado, y que en el conjunto de la UE, con lo que el mismo gasto resulta siempre, en relación al PIB, más bajo en el contexto vasco. Además, es preciso tener en cuenta que hay más menores en España que en Euskadi (los menores de 15 años de Euskadi son un 13,5\% de la población frente al 14,9\% de España). También es necesario subrayar que el diferencial básico entre el Estado y la CAPV se vincula a las prestaciones en efectivo, claramente condicionadas por la política estatal de subsidios familiares vinculados a la renta, circunstancia que beneficia más a zonas con menores ingresos que los de Euskadi.

Por otra parte, desde el punto de vista de la distribución del gasto, existen diferencias relativamente importantes: mientras que Euskadi destina el $66 \%$ del gasto a los servicios de atención directa ( $y$, de ellos, más de la mitad, a la educación infantil), y sólo un $34 \%$ a las prestaciones económicas, en el caso español éstas suponen el $39 \%$ de todo el gasto, y los servicios de atención directa, incluyendo la educación infantil, el $61 \%$.

Euskadi, en definitiva, destina por cada persona menor de edad una cantidad más elevada que el conjunto del Estado a las prestaciones y servicios de ayuda a las familias, lo que sitúa a esta comunidad autónoma a la cabeza del Estado en cuanto a estas políticas se refiere. El hecho de que el esfuerzo en relación al PIB sea menor debe matizarse teniendo en cuenta el mayor peso de los menores en España, la orientación diferencial de las prestaciones en efectivo a favor de los colectivos -y por tanto, de las regiones-con menores recursos, y la dimensión familiar de políticas como la renta de garantía de ingresos que actúan en términos compensatorios y que, de tenerse en cuenta en las estadísticas manejadas, habrían mejorado considerablemente la posición relativa de la CAPV en cuanto al gasto en políticas de apoyo a las familias, con independencia del indicador utilizado ${ }^{9}$.

Cuando la comparación se realiza con el resto de los países de Europa, y se limita al gasto en protección social, las diferencias son todavía más abultadas. Mientras los países más adelantados destinan entre un $2,5 \%$ y un $3 \%$ de su PIB a estas prestaciones, $y$ el conjunto del Estado como se ha dicho un 1,36\%, la CAPV destina un 0,6\% de su PIB a estas ayudas. La situación es muy similar si, en lugar de analizar el gasto en relación al PIB, se analiza en relación al conjunto del gasto en protección social. Euskadi destina un 3,05\% de todo el gasto en protección social a esta función, frente al $8 \%$ de la UE-27 y el 12,6\% de Noruega. Alcanzar la media de la UE-15 supondría, prácticamente, multiplicar el gasto por cuatro, pasando de los 406 millones de euros consignados en 2008 a cerca de 1.600 millones, lo que en las actuales circunstancias económicas puede considerarse un reto imposible de alcanzar.

${ }^{9}$ Como se ha señalado previamente, en 2012 el número de menores de 16 años pertenecientes a familias perceptoras de la RGI era de 24.370 , que representan el $8 \%$ de los menores de esa edad en Euskadi. En total, el $27 \%$ de las familias perceptoras de la RGI tienen a su cargo a menores de 16 años y se destina a ellas un gasto que ronda los 160 millones de euros, que representan en torno al $40 \%$ de todo el gasto en RGI. Por otra parte, En ese sentido, en la CAPV, en 2010 se beneficiaban de estas prestaciones un 6,2\% de los menores de 18 años, frente al o,6\% de la Comunidad Valenciana, el 1,6\% de Andalucía, el 1,1\% de Aragón o el 1,4 de la Comunidad de Madrid. Así, por ejemplo, si se compara la Comunidad de Madrid con la CAPV, el gasto por cada menor de edad beneficiario/a de la RGI sería, en la primera, de 3.100 euros, mientras que en la CAPV superó los 13.000 euros anuales. Los datos se refieren al año 2010. 


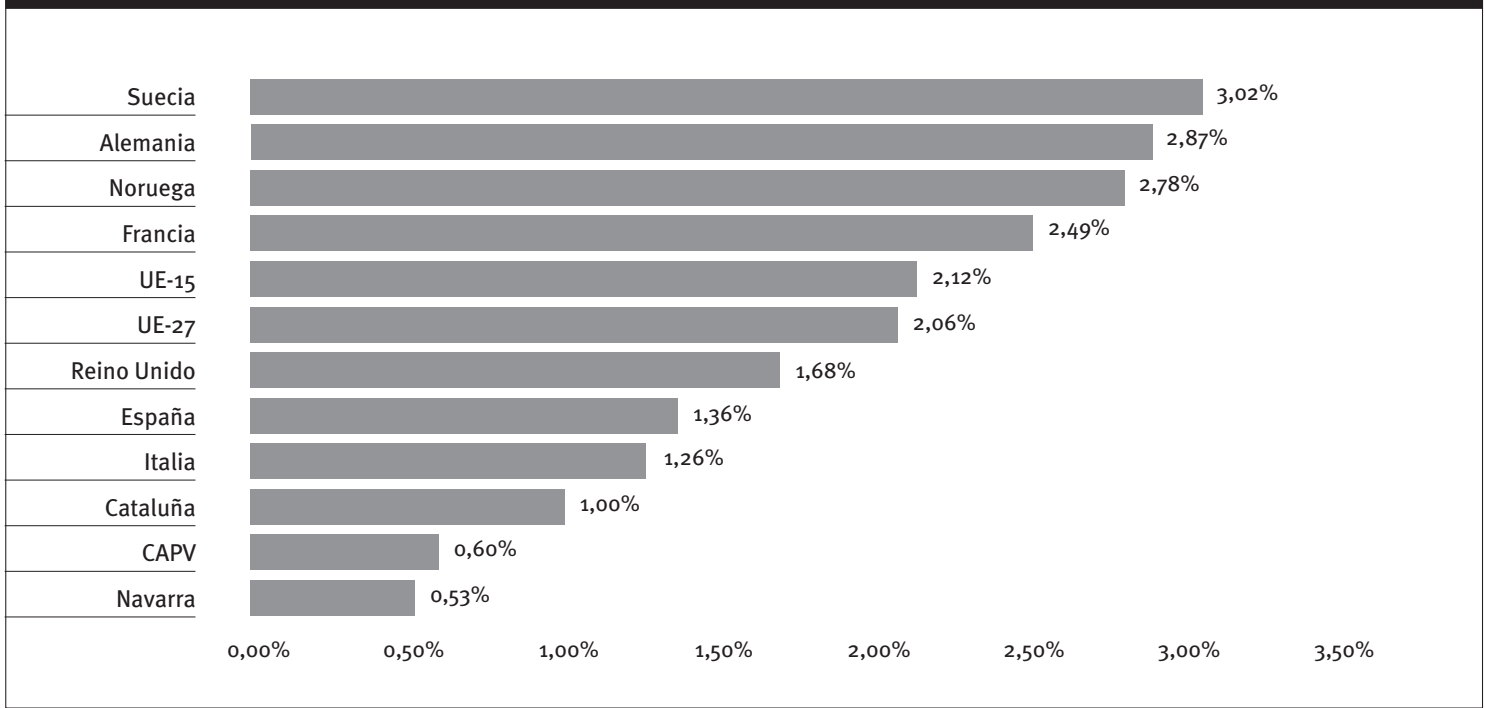

Fuente: Elaboración propia a partir de Eurostat, INE y Eustat.

Gráfico 5. Gasto en la función familia/hijos, por países o comunidades autónomas en 2008 (en \% del gasto en protección social)

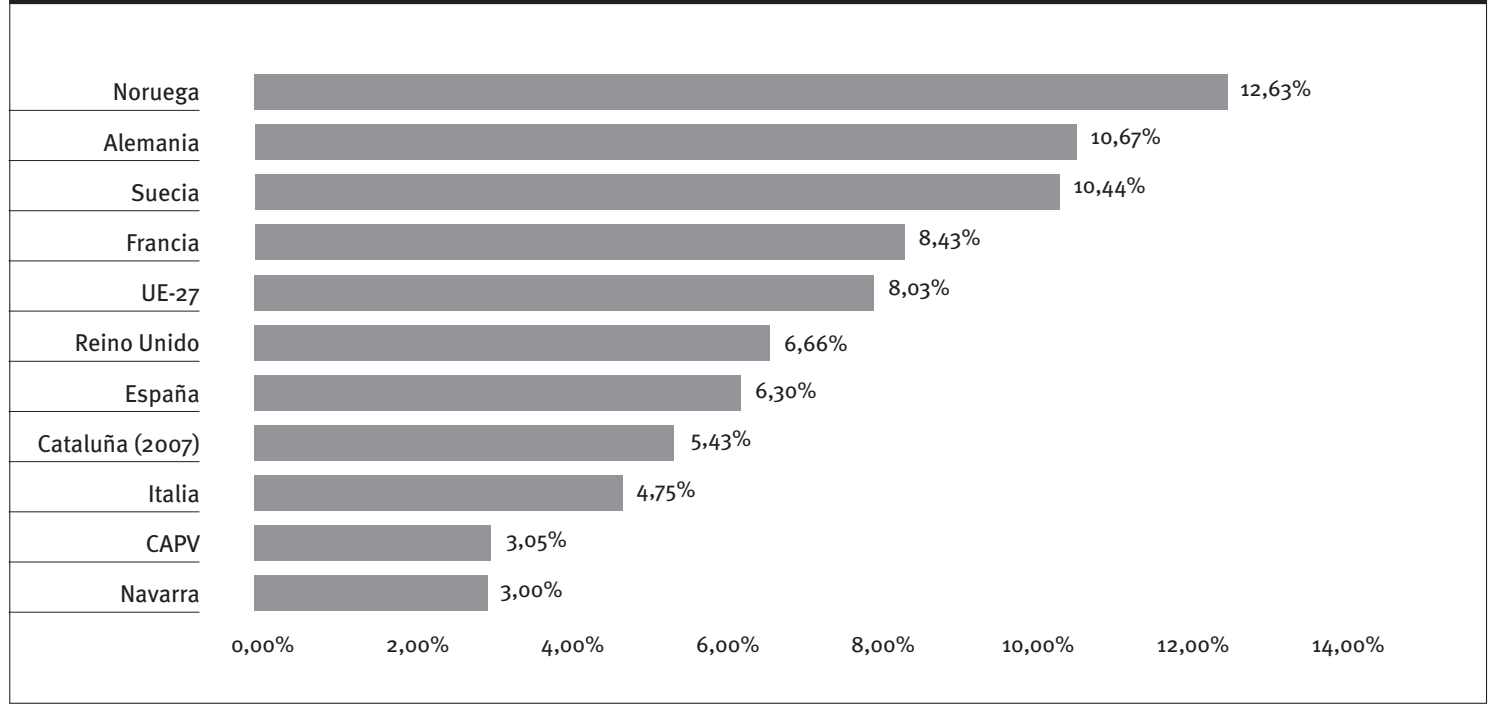

Fuente: Elaboración propia a partir de Eurostat, INE y Eustat.

La cuestión relevante es que Euskadi no sólo gasta menos que la media de la UE en protección social, sino que en el ámbito de la familia la diferencia con la UE es todavía más acusada que en el caso de las demás políticas sociales. Efectivamente, Euskadi destina a todas las prestaciones de protección social -salvo, desempleo y supervivientes- una proporción del PIB menor que el conjunto de la UE. Pero es precisamente en la función de familia, junto a la de vivienda, donde la diferencia es mayor. Si, por ejemplo, en la función de vejez la CAPV gasta en torno a un $75 \%$ de la media UE y en exclusión un $83 \%$, en el ámbito de la familia sólo se gasta, en términos de relación al PIB, un 30\% de lo que se gastaría en caso de convergencia con la UE.
Cuando se tiene en cuenta -como se ha hecho al comparar el gasto vasco con el español-, junto al gasto en protección social el presupuesto destinado a la educación infantil, la situación de conjunto cambia de forma relativamente importante, tal y como se observa en la Tabla 6. Pese a ello, las diferencias siguen siendo grandes, ya que el gasto de los países de la UE-15 en estas partidas asciende al 2,25\% de la UE, frente al $1 \%$ de la CAPV. Una quincena de los países analizados registras porcentajes de gasto superiores al $2 \%$, duplicando por tanto el esfuerzo de la CAPV en estas materias. Aunque las diferencias son menores $-y$ hay una decena de países con un gasto inferior-, Euskadi también se encuentra por debajo de la media de la UE-15 en lo que se refiere al 
Tabla 6. Gasto en políticas de apoyo a las familias, por países. UE, 2007 (en \% del PIB)

\begin{tabular}{|c|c|c|c|c|c|c|c|}
\hline & Total gasto & $\begin{array}{c}\text { Total } \\
\text { efectivo }\end{array}$ & $\begin{array}{c}\text { Total } \\
\text { especie }\end{array}$ & & Total gasto & $\begin{array}{c}\text { Total } \\
\text { efectivo }\end{array}$ & $\begin{array}{c}\text { Total } \\
\text { especie }\end{array}$ \\
\hline Hungría & 3,64 & 2,26 & 1,39 & Eslovaquia & 2,02 & 1,41 & 0,60 \\
\hline Dinamarca & 3,04 & 1,48 & 1,56 & Rumanía & 1,90 & 1,03 & 0,87 \\
\hline Francia & 2,96 & 1,99 & 0,97 & Bulgaria & 1,89 & 0,84 & 1,05 \\
\hline Alemania & 2,86 & 2,03 & 0,83 & Eslovenia & 1,81 & 1,22 & 0,59 \\
\hline Luxemburgo & 2,79 & 2,66 & 0,13 & Letonia & 1,80 & 0,97 & 0,83 \\
\hline Austria & 2,78 & 2,22 & 0,56 & Estonia & 1,78 & 1,32 & 0,46 \\
\hline Bélgica & 2,71 & 1,68 & 1,03 & Reino Unido & 1,69 & 1,13 & 0,56 \\
\hline Suecia & 2,59 & 1,49 & 1,10 & Lituania & 1,68 & 0,84 & 0,84 \\
\hline Irlanda & 2,58 & 2,31 & 0,27 & Países Bajos & 1,60 & 0,61 & 1,00 \\
\hline Noruega & 2,43 & 1,36 & 1,07 & Italia & 1,54 & 0,71 & 0,83 \\
\hline Finlandia & 2,29 & 1,51 & 0,78 & Suiza & 1,48 & 1,06 & 0,42 \\
\hline Chipre & 2,26 & 1,64 & 0,62 & Portugal & 1,39 & 0,73 & 0,66 \\
\hline UE-15 & 2,25 & 1,40 & 0,84 & España & 1,38 & 0,54 & 0,85 \\
\hline Islandia & 2,25 & 1,41 & 0,84 & Grecia & 1,31 & 0,99 & 0,32 \\
\hline Malta & 2,23 & 0,94 & 1,30 & Polonia & 1,29 & 0,79 & 0,50 \\
\hline Chequia & 2,11 & 1,44 & 0,67 & CAPV & 1,00 & 0,34 & 0,66 \\
\hline
\end{tabular}

*El gasto SEEPROS en guarderías no se tiene en cuenta debido a que se incluye dentro del gasto en educación infantil.

Fuente: Elaboración propia a partir de la Cuenta de la Protección Social y la Cuenta de la Educación de Eustat, Eurostat y cuentas integradas sobre protección social del Ministerio de Empleo y Seguridad Social.

gasto en servicios de atención directa, incluso una vez incluido el gasto en educación infantil.

\subsubsection{Un gasto fundamentalmente basado en las desgravaciones fiscales, y no en las prestaciones 0 en los servicios de atención directa}

Una forma alternativa de analizar el gasto público destinado a las familias es tener también en cuenta el gasto fiscal, es decir, las deducciones y desgravaciones practicadas en el sistema impositivo como herramienta de apoyo a las familias (mediante la fórmula de las deducciones por descendientes, por ejemplo). En el caso de la CAPV, resulta importante tener en cuenta este tipo de gastos fiscales, ya que, de acuerdo a la memoria del Plan de Apoyo a las Familias con Hijos/as, las haciendas forales de la CAPV destinaron en 2008 un total de 237 millones de euros a las políticas de apoyo a las familias (en realidad, dejaron de ingresar esa cantidad, ya que se trata de cantidades descontadas de las respectivas declaraciones de IRPF).

Para calcular ese tipo de gasto, se ha añadido a los datos recogidos anteriormente el gasto fiscal que, según la OCDE, realizan los países de Europa en exenciones y desgravaciones tributarias directamente relacionadas con la política de apoyo a las familias. Para la CAPV, se han utilizado los datos recogidos en las tablas anteriores $y$, para el gasto fiscal, los que se indican en la memoria del Plan de Familia. Sin embargo, aun teniendo en cuenta este tipo de gasto, si se observa el conjunto del gasto público en políticas de apoyo a las familias en relación al PIB, la CAPV se situaría a la cola de los países de la UE. Mientras el gasto total asciende en Francia al 3,68\% del PIB, en Alemania al 3,74\% y en Bélgica al 3,29\%, en el caso de la CAPV el gasto total equivaldría al 1,34\% del PIB, por detrás de los países de la UE analizados. El esfuerzo que realizan Francia y Alemania, por ejemplo, casi triplicaba en 2007 el que se realizaba en la CAPV.

Tabla 7. Gasto público en la función familia, por países y tipo de gasto. UE, 2007 (en \% del PIB)

\begin{tabular}{l|c|c|c|c}
\cline { 2 - 5 } & $\begin{array}{c}\text { Prestaciones } \\
\text { en metálico }\end{array}$ & Servicios & $\begin{array}{c}\text { Desgravaciones } \\
\text { fiscales }\end{array}$ & Total \\
\hline Alemania & 2,03 & 0,83 & 0,88 & 3,74 \\
\hline Francia & 1,99 & 0,97 & 0,72 & 3,68 \\
\hline Bélgica & 1,68 & 1,03 & 0,58 & 3,29 \\
\hline Dinamarca & 1,48 & 1,56 & 0,00 & 3,04 \\
\hline Austria & 2,22 & 0,56 & 0,04 & 2,82 \\
\hline Luxemburgo & 2,66 & 0,13 & 0,00 & 2,79 \\
\hline Irlanda & 2,31 & 0,27 & 0,11 & 2,69 \\
\hline Suecia & 1,49 & 1,10 & 0,00 & 2,59 \\
\hline República Checa & 1,44 & 0,67 & 0,47 & 2,58 \\
\hline Noruega & 1,36 & 1,07 & 0,10 & 2,53 \\
\hline Países Bajos & 0,61 & 1,00 & 0,85 & 2,45 \\
\hline Eslovaquia & 1,41 & 0,60 & 0,41 & 2,43 \\
\hline Finlandia & 1,51 & 0,78 & 0,00 & 2,29 \\
\hline Reino Unido & 1,13 & 0,56 & 0,33 & 2,02 \\
\hline Polonia & 0,79 & 0,50 & 0,50 & 1,79 \\
\hline España & 0,54 & 0,85 & 0,24 & 1,62 \\
\hline Suiza & 1,06 & 0,42 & 0,14 & 1,62 \\
\hline Portugal & 0,73 & 0,66 & 0,17 & 1,56 \\
\hline Italia & 0,71 & 0,83 & 0,00 & 1,54 \\
\hline CAPV & 0,34 & 0,66 & 0,34 & 1,34 \\
\hline & & & & \\
\hline
\end{tabular}

Fuente: Elaboración propia a partir de datos de Eustat, Eurostat y OCDE. 
Junto al escaso volumen de gasto total en relación al PIB, una de las particularidades del gasto vasco en familia, cuando se tienen en cuenta las desgravaciones fiscales, es el importante peso que estas últimas juegan en el conjunto del gasto. En efecto, sólo Polonia y Países Bajos recurren en mayor proporción, a la hora de configurar su paquete de apoyo a las familias, a las desgravaciones fiscales. Alemania también lo hace en una medida importante (23\% del gasto), aunque queda en cualquier caso por debajo que este tipo de medidas tienen en Euskadi (25,4\% de todo el gasto). El principal inconveniente de un peso excesivo de los gastos fiscales en el conjunto del gasto en las políticas de apoyo a las familias radica en el hecho de que las familias con menos ingresos se benefician en menor medida de estas exenciones y desgravaciones, dado que en ningún caso estas ayudas superan las cantidades retenidas a cuenta por la Hacienda pública, y que las retenciones de las unidades familiares de menor renta son menores que las de las familias con mayor renta o, incluso, no se realizan, con lo que no pueden beneficiarse de este tipo de ayudas.

Tabla 8. Distribución del gasto público en la función familia, por países y tipo de gasto. UE, 2007 (\%)

\begin{tabular}{l|c|c|c}
\cline { 2 - 4 } & $\begin{array}{c}\text { Prestaciónes } \\
\text { en metálico }\end{array}$ & Servicios & $\begin{array}{c}\text { Desgravaciones } \\
\text { fiscales }\end{array}$ \\
\hline Alemania & 54,3 & 22,1 & 23,5 \\
\hline Francia & 54,2 & 26,2 & 19,6 \\
\hline Bélgica & 51,1 & 31,3 & 17,6 \\
\hline Dinamarca & 48,8 & 51,2 & 0,0 \\
\hline Austria & 78,7 & 19,9 & 1,4 \\
\hline Luxemburgo & 95,4 & 4,6 & 0,0 \\
\hline Irlanda & 85,7 & 10,2 & 4,1 \\
\hline Suecia & 57,6 & 42,4 & 0,0 \\
\hline República Checa & 55,7 & 26,1 & 18,2 \\
\hline Noruega & 53,9 & 42,1 & 4,0 \\
\hline Países Bajos & 24,7 & 40,6 & 34,7 \\
\hline Eslovaquia & 58,3 & 24,9 & 16,9 \\
\hline Finlandia & 66,1 & 33,9 & 0,0 \\
\hline Reino Unido & 55,9 & 27,8 & 16,3 \\
\hline Polonia & 44,3 & 27,9 & 27,9 \\
\hline España & 33,0 & 52,3 & 14,8 \\
\hline Suiza & 65,3 & 26,1 & 8,6 \\
\hline Portugal & 46,9 & 42,2 & 10,9 \\
\hline Italia & 46,0 & 54,0 & 0,0 \\
\hline CAPV & 25,4 & 49,3 & 25,4 \\
\hline
\end{tabular}

Fuente: Elaboración propia a partir de datos de Eustat, Eurostat y OCDE.

La diferencia entre el modelo vasco y el de la media de los países de la UE se pone de manifiesto en los Gráficos 6 y 7: en relación al gasto medio de la UE, el gasto vasco representa apenas un $55 \%$; sin embargo, en el caso de las prestaciones el gasto vasco sólo llega al $25 \%$ de la media, mientras que en el caso de los servicios de atención directa llega al 87\% y en lo que se refiere a las desgravaciones alcanza el $115 \%$. Desde el punto de vista de la distribución del gasto, mientras que en Euskadi las prestaciones económicas apenas representan el $25 \%$ del gasto, en la media del conjunto de los países suponen un $57 \%$. Al contrario, el $49 \%$ del gasto vasco se destina a servicios de atención directa, frente al 31\% de la media; y el $25 \%$, a desgravaciones fiscales, frente al $12 \%$ en la UE.

Gráfico 6. Proporción del gasto en apoyo a las familias en relación a la UE*. CAPV, 2007 (\%)

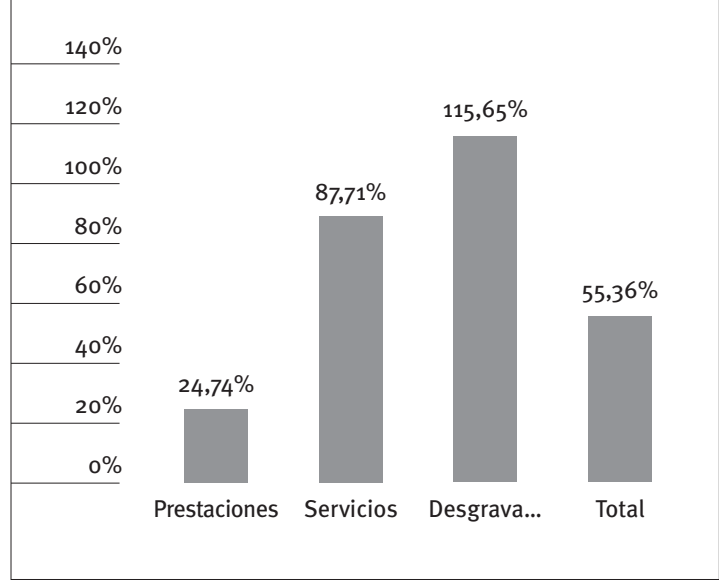

* UE $=100$.

Fuente: Elaboración propia a partir de datos de Eustat, Eurostat y OCDE.

Gráfico 7. Distribución del gasto en políticas de apoyo a las familias. UE y CAPV, 2007 (\%)

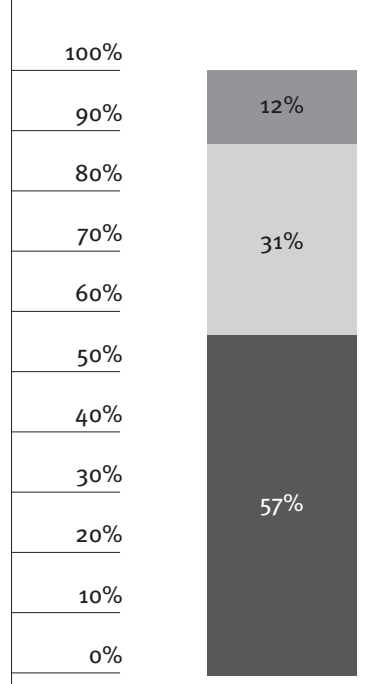

UE

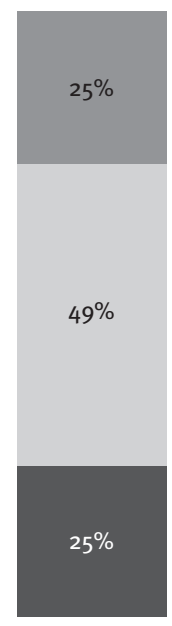

CAPV

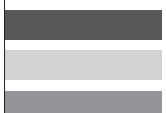

Prestaciones en métalico Servicios

Desgravaciones fiscales

Fuente: Elaboración propia a partir de datos de Eustat, Eurostat y OCDE. 
A la hora de contextualizar las diferencias entre Euskadi y el conjunto de los países de la UE es necesario en cualquier caso tener en cuenta que las políticas familiares europeas tienen una notable dimensión universalista, asociada a unos ingresos públicos muy elevados, que hace difícil comparar esas políticas con lo que se hace en España y en Euskadi, con un gasto mucho más selectivo asociado a ingresos públicos muy inferiores. No hay que olvidar, en ese sentido, que el ingreso de las administraciones públicas en 2008 en España y Euskadi estaba en torno al 37-38\% del PIB frente a cerca de un $49,9 \%$ en Francia, por ejemplo. Es lógico por tanto que retorne a la ciudadanía mediante servicios y prestaciones una parte más elevada del PIB. Así pues, para poder hacer comparaciones reales, ese efecto devolución vía políticas universalistas hacia la infancia debería ser de alguna forma aislado. De hecho, si el porcentaje de ingresos sobre el PIB fuera en Euskadi el mismo que en Francia, a igualdad de estructura de gasto, frente a un gasto en familia tres veces superior en Francia al observado en Euskadi, la relación entre el gasto estandarizado sin déficit se reduciría a una diferencia de 1,5 a favor de Francia, cifra esta última que refleja mejor el esfuerzo diferencial de gasto respecto a ingresos/necesidades reales que se realiza en cada ámbito. Si se tuviera en cuenta el efecto de las políticas de garantía de ingresos, la diferencia sería probablemente menor, además.

Sirva esto únicamente para señalar que, sin tener en cuenta el conjunto de las políticas sociales, el nivel y las estructuras de ingresos y gastos de las administraciones públicas, así como los resultados de las acciones sociales sobre los ingresos familiares, las comparaciones que pueden realizarse tienen un carácter meramente orientativo y necesariamente parcial. Sería, por tanto, conveniente avanzar en este ámbito mediante el desarrollo de metodologías que tengan en cuenta, para los diversos países, tanto la aportación que realiza la ciudadanía vía impuestos como los servicios y prestaciones que reciben, con lo que se podría extraer el efecto neto de estas políticas, en cada país, para el conjunto de la ciudadanía y para los diversos grupos sociodemográficos y de renta ${ }^{10}$.

\section{Conclusiones y recomendaciones}

\subsection{Conclusiones}

\subsubsection{El gasto vasco en apoyo a las familias es inferior al que se realiza en los países de la UE, aunque superior al que se realiza en el Estado español}

El análisis realizado en relación al gasto en el ámbito de las políticas familiares ha puesto de manifiesto que, si se compara con el esfuerzo que realizan los países de la UE que han sido examinados, el gasto destinado en Euskadi a estas políticas es muy bajo.

${ }^{10}$ Enfoques de este tipo han sido desarrollados por autores como J. Bradshaw mediante la comparación de los 'paquetes' de servicios que reciben distintas composiciones familiares típicas, o mediante el recurso a herramientas de microsimulación, como el proyecto Euromod.
Mientras que Francia, nuestro país vecino, destina, por ejemplo, un 3,68\% de su PIB a este tipo de políticas, en la CAPV apenas se le destina el 1,34\%. En ambos casos, se incluyen los gastos fiscales derivados de las exenciones y desgravaciones por descendientes que existen en el sistema tributario, así como las prestaciones y los servicios en especie, incluyendo la educación infantil. Si el sistema vasco se caracteriza por un gasto reducido en el conjunto de la protección social, el déficit es todavía más acusado en el ámbito de las políticas de apoyo a las familias, que constituyen -en consonancia con el carácter mediterráneo del Estado de bienestar imperante en nuestro país- un ámbito particularmente poco desarrollado. Una segunda característica, desde el punto de vista del gasto, de las políticas de apoyo a las familias en la CAPV es el peso que en ellas tienen los gastos fiscales, que sin duda benefician especialmente a las familias de rentas medias y altas, en detrimento de las familias con rentas más bajas.

El análisis realizado no permite establecer con claridad en qué medida el atraso detectado en Euskadi es atribuible a las instituciones autonómicas, a las estatales o a ambas. Tampoco era ése el objetivo del informe. En cualquier caso, parece claro que en la mayor parte de los países analizados las políticas de apoyo a las familias vienen determinadas a nivel estatal, y son desarrolladas por las cajas de la Seguridad Social. Desde ese punto de vista, puede pensarse que el importante esfuerzo de gasto realizado en los últimos años por el Gobierno Vasco mediante los sucesivos planes de apoyo a las familias con hijos/as ha sido insuficiente para compensar el escaso gasto realizado por la Seguridad Social en este ámbito, cuyas prestaciones se caracterizan por cuantías muy reducidas y un carácter claramente selectivo, como se señala más adelante.

En cualquier caso, la situación de la CAPV en el contexto europeo resulta muy particular, pues se distingue por registrar los niveles de gasto y las tasas de fecundidad más bajas de los países europeos de la OCDE, tal y como pone de manifiesto el Gráfico 8. Además, el gráfico muestra claramente que existe una relación positiva entre fecundidad y gasto en políticas de apoyo a las familias. Obviamente, esos datos no establecen una relación causal y no indican que, a mayor gasto en familia, mayor será la tasa de fecundidad. Perfectamente podría ocurrir al contrario. Lo que sí parece claro es que ambos elementos van de la mano y que una tasa de fecundidad elevada - para los actuales parámetros europeos- lleva aparejado un gasto social mucho más elevado que el que en la actualidad realiza la CAPV.

\subsubsection{Un sistema prestacional más desarrollado que en las comunidades autónomas españolas, pero muy alejado de los estándares europeos}

El repaso de las prestaciones de apoyo a las familias con hijos/as desarrollado en el informe que sirve de base a este artículo permite asegurar que, al menos 


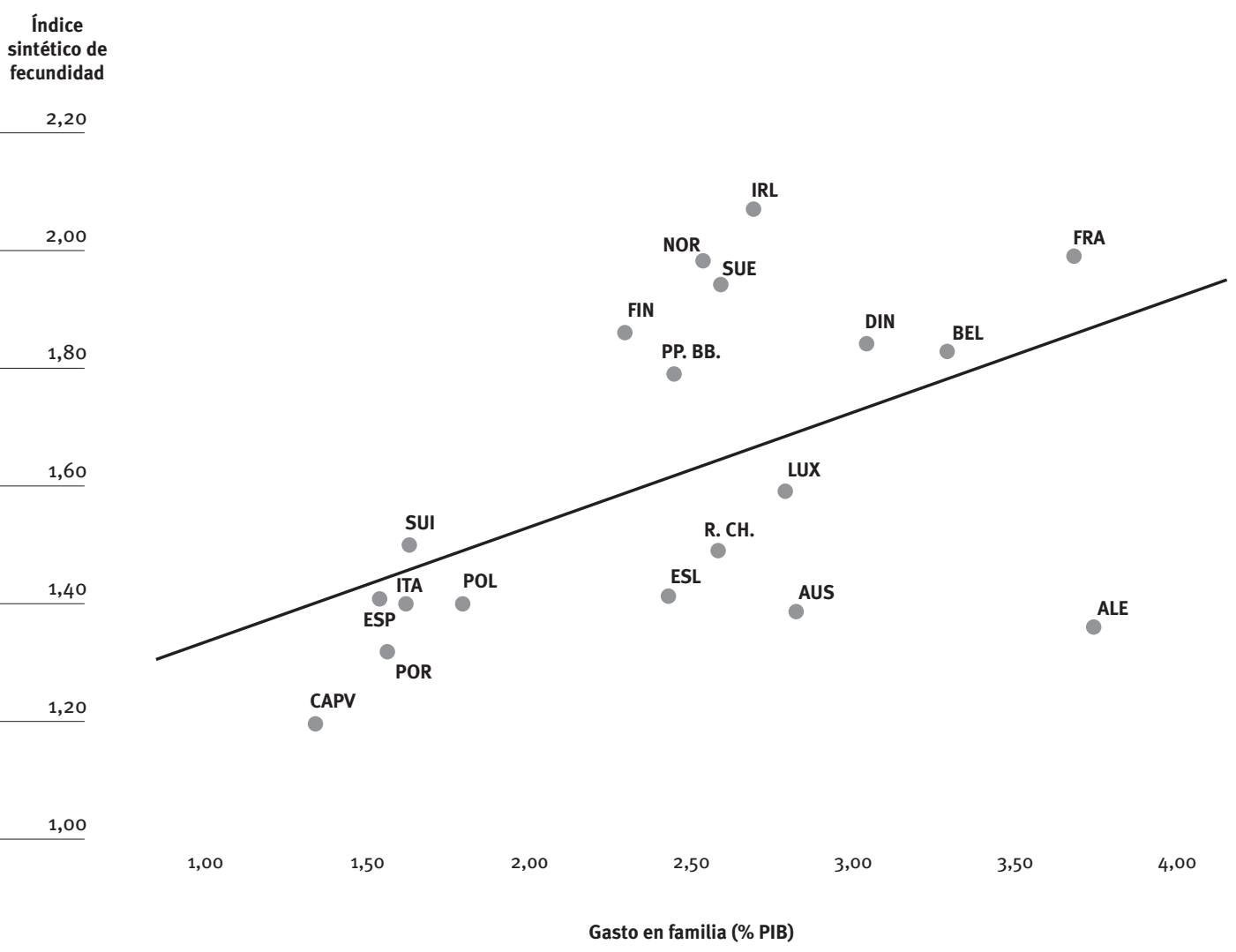

Fuente: Elaboración propia a partir de datos de Eustat, Eurostat y OCDE.

en relación a las comunidades autónomas analizadas, Euskadi cuenta con una política más amplia y desarrollada. De hecho, la CAPV es en la actualidad la única comunidad autónoma que mantiene ayudas económicas de carácter universal para las familias con hijos/as. Sin embargo, si la comparación se realiza con los países de Europa, se observa un desarrollo sustancialmente menor, con menos ayudas y, cuando éstas existen, con ayudas de menor cuantía, de menor duración y, muy a menudo, de carácter selectivo.

Las conclusiones que se extraen del análisis realizado son las siguientes:

- En una parte fundamental, las políticas de apoyo a las familias que se aplican en Euskadi vienen determinadas por las políticas adoptadas a nivel estatal, ya que tanto la regulación de las excedencias y los permisos por maternidad o paternidad, como la regulación de las prestaciones económicas por maternidad y por hijo a cargo vienen determinadas a nivel estatal. Aunque las políticas autonómicas juegan un papel cada vez más importante a la hora de establecer el marco de apoyo a las familias, su incidencia es, por tanto, todavía reducida, al menos desde el punto de vista del gasto.
- En ese marco, y teniendo en cuenta tanto las prestaciones estatales como las autonómicas, puede decirse que las familias que residen en Euskadi se benefician de una política de ayudas más desarrolladas que en Italia o que en las demás comunidades autónomas españolas.

- En relación a Alemania, Francia, Suecia y Noruega, sin embargo, la situación imperante en la CAPV se caracteriza por:

- Bajas por maternidad similares a las de los países del centro de Europa, pero más cortas que en los países nórdicos. La baja por maternidad que existe en Euskadi -determinada por la legislación estatal- es de 16 semanas de duración, similar a la italiana o la francesa, pero mucho más corta que la sueca (68 semanas) o la noruega (47 semanas con el $100 \%$ del salario 057 con el $80 \%$ ).

- Menor cuantía de las ayudas por excedencia. Debido a la duración de las bajas por maternidad, los países nórdicos carecen propiamente hablando de prestaciones económicas para el caso de las excedencias. Alemania, por el contrario contempla una ayuda de doces meses (Elterngeld), que garantiza el $67 \%$ del sueldo, con un mínimo de 300 euros, mientras que en Francia el complemento de libre elección de actividad ofrece ayudas que pueden llegar 
hasta los 560 euros mensuales. En la CAPV, las ayudas económicas en caso de excedencia son de 271 euros mensuales.

- Práctica ausencia de una prestación universal por hijo/a a cargo de carácter periódico. Probablemente, la mayor diferencia entre la CAPV y los países analizados es la ausencia en la práctica de una prestación periódica por hijo/a cargo. Las únicas prestaciones existentes son la financiada por la Seguridad Social, de carácter estrictamente selectivo y con una cuantía muy reducida, y la que se concede a nivel autonómico a las familias de tres o más hijos/as. El plazo de recepción de esa ayuda (hasta los 7 años) y su cuantía (75 euros mensuales por todos los hijos/as) difiere sustancialmente de los modelos aplicados en Europa. Francia, Alemania, Suecia y Noruega disponen de ayudas para todos/as los niños/as (salvo en Francia, donde se empieza a percibir a partir del segundo/a), que se extiende en general hasta la mayoría de edad y rondan, en la mayor parte de los países, los 125 euros mensuales. El derecho a esta prestación en los países analizados es universal, si bien en algunos casos la cuantía depende del nivel de renta ${ }^{11}$.

- Escaso desarrollo de las prestaciones para la financiación del cuidado infantil a domicilio por parte de terceras personas. A diferencia, por ejemplo, de lo que ocurre en Francia, Euskadi carece en la práctica de una prestación que permita financiar parcialmente el gasto que supone la contratación de personas cuidadoras, bien en el domicilio de los niños/ as, bien en el de las cuidadoras, mediante el recurso a profesionales acreditadas, que cuidan a un grupo de niños/as en su propio domicilio $^{12}$. La prestación francesa es de carácter universal, aunque supeditada al nivel de renta, y ofrece cuantías relativamente altas. En el caso de Suecia la prestación es de 329 euros mensuales, y en Noruega oscilan entre 88 y 443 euros, en función de si el niño/a asiste a un centro de educación infantil. Las ayudas que en este sentido existen en la CAPV sólo incluyen una parte, en función del nivel de renta, de los costes de Seguridad Social de la persona contratada.

- Peso importante de las subvenciones a centros de educación infantil. Al igual que el resto de la mayor parte de las comunidades autóno-

\footnotetext{
${ }^{11}$ Aplicar estas política en Euskadi requeriría un gasto adicional cercano a los 480 millones de euros, lo que supondría multiplicar por 2,1 el gasto que se realiza en la actualidad. Y aun así, el gasto en relación al PIB seguiría estando entre los más bajos de los países analizados.

${ }^{12}$ Las denominadas madres de día son una alternativa muy extendida en la mayor parte de los países de Europa y, particularmente, en Francia. Consiste en la atención, en el domicilio de una cuidadora profesional acreditada, de un grupo reducido de niños/as. Este tipo de servicios existe en Francia (assistante maternelle), Suiza (mamans de jour), Alemania (Tagesmutter) o Reino Unido (child minder). En el Estado español, existen iniciativas de este tipo en Aragón, Andalucía, Navarra y la CAPV, mediante el programa de Nidos Familiares.
}

mas, Euskadi ha desarrollado una línea de ayudas a los centros infantiles que atienden a niños/as de o a 3 años, y a sus familias. En el caso de las ayudas a las familias, el carácter de las ayudas es selectivo y sólo se conceden a las familias de menor renta.

- Mayor desarrollo de las prestaciones por nacimiento. En ausencia de un sistema de asignaciones periódicas por hijo/a a cargo, Euskadi, al igual que el conjunto de España, ha optado por la concesión de ayudas de pago único en caso de nacimiento, que, lógicamente, cubren en mucha menor medida los gastos derivados de la atención infantil.

\subsection{Recomendaciones}

Las principales conclusiones que cabe sacar de este informe son dos:

- No puede decirse que en Euskadi se estén dando todos los pasos necesarios para adoptar el paradigma del Estado social inversor al que se ha hecho referencia en la primera parte de este artículo. Por una parte, pese al esfuerzo realizado en los últimos años por las instituciones autonómicas, el gasto que se destina a las políticas de apoyo a las familias con hijos/as es muy bajo. Por otra, estas políticas resultan todavía secundarias en relación al conjunto de la protección social y están lejos de la centralidad que en otros países parecen estar alcanzado.

- El modelo de prestaciones y servicios que existe en la CAPV está muy escasamente desarrollado si se compara con el que existe en la mayor parte de los países analizados (Francia, Alemania, Suecia y Noruega, concretamente). En ese sentido, y en relación a esos países, el sistema vasco se caracteriza por la ausencia de una prestación económica periódica, de carácter universal, por hijo/a a cargo; la escasa cuantías de las prestaciones económicas que favorecen las excedencias y reducciones de jornada; y la debilidad de las prestaciones dirigidas a facilitar la contratación de personas cuidadoras, ya sea en el su domicilio, ya sea en el de los niños/as.

Obviamente, la situación económica actual impide una modificación sustancial de las actuales políticas vascas de apoyo a las familias, en la medida en que implican un incremento muy sustancial del gasto público que se destina a esta materia. En cualquier caso, pueden apuntarse en el contexto actual algunas orientaciones que deberían ir aplicándose a medio plazo, a medida que la situación económica lo permita:

- Desde el punto de vista más global, es necesario plantear un cambio general de orientación del modelo de protección social que se aplica en la CAPV, adoptando como criterio general válido el paradigma del Estado social inversor. Ello implica, 
por una parte, la necesidad de impulsar las políticas de apoyo a las familia y, por otra, la necesidad de evaluar las políticas de protección social en términos de eficiencia, priorizando aquellas que pueden demostrarse más beneficiosas para el conjunto de la sociedad.

- Desde un punto de vista más específico, sería deseable avanzar en tres sentidos:

- Creación progresiva de una asignación periódica por hijo/a a cargo, que cubra al menos hasta los 16 años de edad y, paralelamente, eliminación de las ayudas de pago único por nacimiento, pasando de un modelo de ayudas puntuales por nacimiento a otro de asignaciones periódicas, de carácter universal, por hijo/a a cargo. Este cambio permitiría la homologación de las políticas vascas de apoyo a las familias con las que se realizan en los países analizados. Podría valorarse la posibilidad, como en Francia, de que las ayudas se conceden a partir del segundo hijo/a y de modular su cuantía en función de la renta, estableciendo en cualquier caso una ayuda mínima para cualquier familia con independencia de su renta.

- Extensión de la cuantía de las ayudas económicas por excedencia, de forma que, siguiendo el modelo alemán, cubran dos terceras partes del salario previo y puedan percibirse durante al menos doce meses, antes de los 3 años de edad.

- Impulso a las subvenciones para la contratación de personas cuidadoras en el domicilio infantil o en el domicilio de las propias personas cuidadoras, siguiendo el modelo aplicado en Francia.

- Eliminación de los criterios de selectividad en las ayudas económicas individuales para la escolarización en centros de o a 3 años.

- Replanteamiento de las políticas de desgravaciones y exenciones tributarias, en la medida en que se vayan estableciendo, para los mismos fines, prestaciones económicas directas. 
BARNETT, W. S. (2006): Research on the Benefits of Preschool Education: Securing High Returns from Preschool for all Children, Nueva York, National Institute for Early Education Research.

BARTIK, T. J. I. (2009): Distributional Effects of Early Childhood Programs and Business Incentives and their Implications for Policy, serie Upjohn Institute Working Papers, no 09-151, Kalamazoo, Upjohn Institute for Employment Research.

BLUM, S.; y RILLE-PFEIFFER, C. (2010): Major Trends of State Family Policies in Europe. Working Report (April 2010), serie Existential Field, no 3 , Bruselas, Family Platform; Comisión Europea.

CHAUFFAUT, D.; y BOYER, D. (2010): “Retombées économiques des politiques d'accueil de la petite enfance. Quelques approches récentes", Politiques Sociales et Familiales, nํㅜ 99, págs. 89-96.

ESPING-ANDERSEN, G. (2009): The Incomplete Revolution. Adapting to Women's New Roles, Cambridge, Policy Press.

- (2007): “Un nuevo equilibrio de bienestar”, Política y Sociedad, vol. 44, nํ2, págs. 11-30.

(2002): "A child-centred social investment strategy", en ESPING-ANDERSEN, G., Why We Need a New Welfare State, Nueva York, Oxford University Press, págs. 26-67.

ESPING-ANDERSEN, G.; y PALIER, B. (2010): “Familia y revolución del papel de la mujer”, en ESPINGANDERSEN, G., Los tres grandes retos del Estado del bienestar, Barcelona, Ariel.

GAULT, B.; y LOVELL, V. (2006): "The costs and benefits of policies to advance work/life integration", American Behavioral Scientist, vol. 49, nำ 9, págs. 1.152-1.164.
GAUTHIER, A. H. (2010): The Impact of the Economic Crisis on Family Policies in the European Union, Bruselas, Comisión Europea.

GÍSLASON, I. V.; y EYDAL, G. B. (eds.) [2011]: Parental Leave, Childcare and Gender Equality in the Nordic Countries, Copenhague, Nordic Council of Ministers.

HECKMAN, J. J. (2006): "Skill formation and the economics of investing in disadvantaged children", Science, $\mathrm{n}^{0} \mathrm{3}$ 312, págs. 1.900-1.902.

HECKMAN, J.; GRUNEWALD, R.; y REYNOLDS, A. (2006): "The dollars and cents of investing early: Costbenefit analysis in early care and education", Zero to Three, julio, págs. 10-17.

HECKMAN, J. J.; y MASTEROV, D. V. (2004): The Productivity Argument for Investing in Young Children, Chicago, Committee for Economic Development.

JENSON, J. (2012): “Redesigning citizenship regimes after neoliberalism: Moving towards social investment", en MOREL, N.; PALIER, B.; y PALME, J. (eds.), Towards a Social Investment Welfare State? Ideas, Policies and Challenges, Bristol, Policy Press, págs. 61-87.

KAROLY, L. A.; y BIGELOW, J. H. (2005): The Economics of Investing in Universal Preschool Education in California, Santa Mónica, RAND Corporation.

LETABLIER, M. T. et al. (2009): The Costs of Raising Children and the Effectiveness of Policies to Support Parenthood in European Countries: A Literature Review, Bruselas, Comisión Europea.

MARTÍNEZ HERRERO, M. J. (2008): “La política familiar como instrumento de igualdad: distintas concepciones europeas", Lan Harremanak, no 18 , págs. 43-79. 
MINISTERIO DE EMPLEO Y SEGURIDAD SOCIAL (2011): Anuario de Estadísticas del Ministerio de Trabajo e Inmigración 2010. Madrid, Ministerio de Empleo y Seguridad Social.

MOREL, N.; PALIER, B.; y PALME, J. (2012): "Beyond the welfare state as we knew it?”, en MOREL, N.; PALIER, B.; y PALME, J. (eds.), Towards a Social Investment Welfare State? Ideas, Policies and Challenges, Bristol, Policy Press, págs. 1-87.

MOREL, N.; PALIER, B.; y PALME, J. (eds.) [2012]: Towards a Social Investment Welfare State? Ideas, Policies and Challenges, Bristol, Policy Press.

MORGAN, K. J. (2012): "Promoting social investment through work family policies: Which nations do it and why?", en MOREL, N.; PALIER, B.; y PALME, J. (eds.), Towards a Social Investment Welfare State? Ideas, Policies and Challenges, Bristol, Policy Press, págs. 153-179.

MUJICA, R. et al. (2006): “Out-of-home day care for families living in a disadvantaged area of London: economic evaluation alongside a RCT", Child:
Care, Health and Development, vol. 32, $\mathrm{n}$ 으, págs. 287-302.

ORGANIZACIÓN PARA LA COOPERACIÓN Y EL DESARROLLO ECONÓMICO (2011): Doing Better for Families, París, Organización para la Cooperación y el Desarrollo Económico.

STEVENS, M. et al. (2010): "Research review. Economic evidence for interventions in children's social care: Revisiting the What Works for Children project”, Child and Family Social Work, vol. 15, no 2 , págs. $145-154$.

WARNER, M. E. (2008): (Not) Valuing Care: A Review of Recent Popular Economic Reports on Early Education in the U.S., Ithaca, Cornell University.

WENDT, C. et al. (2011): Welfare States and Public Opinion. Perceptions of Healthcare Systems, Family Policy and Benefits for the Unemployed and Poor in Europe, Cheltenham, Edward Elgar.

ZUBIAUR, J. M. (2008): Hacia un nuevo modelo de protección a las familias en España, Madrid, Ministerio de Trabajo e Inmigración.

\section{Nota metodológica}

\section{Definición de las prestaciones contempladas en la función familia e hijos/as de SEEPROS ${ }^{13}$}

- Mantenimiento de rentas durante la maternidad. Recoge el gasto por prestación de maternidad pagado por el sistema de la Seguridad Social, las empresas y las administraciones públicas a sus empleados. En el caso de la CAPV, incluye también las ayudas económicas a la conciliación laboral concedidas por el Departamento de Empleo y Asuntos Sociales del Gobierno Vasco.

- Permiso parental. A partir del año 2007, se recoge el gasto de la nueva prestación económica por paternidad. En el informe, este gasto se ha incorporado al epígrafe otras prestaciones en efectivo.

- Asignación familiar por hijo a cargo. Recoge las prestaciones familiares del sistema de la Seguridad Social y de los distintos sistemas de protección social de los funcionarios. Las prestaciones familiares están sometidas a condición de recursos, salvo en el caso de hijos con una discapacidad igual o superior al $65 \%$. Para el territorio de régimen común, a partir del año 2003 se incluye la deducción por maternidad del IRPF a mujeres que trabajan fuera del hogar con hijos menores de 3 años. En el caso de la CAPV, se incluyen en este epígrafe las ayudas económicas por nacimiento o por hijo/a a cargo concedidas por el Departamento de Empleo y Asuntos Sociales del Gobierno Vasco.

- Subsidio de natalidad. Recoge las prestaciones por nacimiento o adopción de tercer o sucesivos hijos, por nacimiento o adopción en supuestos de familias numerosas, monoparentales y madres discapacitadas, por parto o adopción múltiple y, a partir del año 2007, la nueva prestación económica por nacimiento o adopción de hijo.

- Otras prestaciones familiares en dinero. Recoge las restantes prestaciones no incluidas en las anteriores, generalmente a cargo de las empresas para sus trabajadores, así como el permiso de paternidad anteriormente señalado.

- Prestaciones en especie. Las prestaciones en especie recogen las prestaciones de servicios sociales prestadas a las familias, otorgadas fundamentalmente por las comunidades autónomas. Bajo la rúbrica de 'cuidado infantil de día', se encuentran los gastos en la etapa de educación infantil proporcionados por el Ministerio de Educación y las administraciones educativas de las comunidades autónomas, y en 'otras prestaciones', se encuentran fundamentalmente las becas concedidas bajo condición de recursos por los mismos agentes.

\footnotetext{
${ }^{13}$ Fuente: Ministerio de Empleo y Seguridad Social, 2011.
} 